NIST Technical Note 1722

\title{
Simple Estimates of Combined Stairwell / Elevator Egress in Buildings
}

\author{
Paul A. Reneke \\ Piotr Tofilo \\ Richard D. Peacock \\ Bryan L. Hoskins
}

http://dx.doi.org/10.6028/NIST.TN.1722

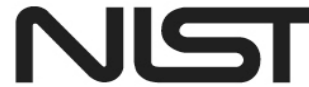


NIST Technical Note 1722

\title{
Simple Estimates of Combined Stairwell / Elevator Egress in Buildings
}

\author{
Paul A. Reneke \\ Piotr Tofilo \\ Richard D. Peacock \\ Bryan L. Hoskins \\ Fire Research Division \\ Engineering Laboratory
}

http://dx.doi.org/10.6028/NIST.TN.1722

February 2013

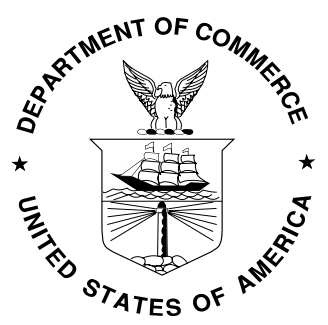

U.S. Department of Commerce

Rebecca Blank, Acting Secretary

National Institute of Standards and Technology Patrick D. Gallagher, Under Secretary of Commerce for Standards and Technology and Director 
Certain commercial entities, equipment, or materials may be identified in this document in order to describe an experimental procedure or concept adequately. Such identification is not intended to imply recommendation or endorsement by the National Institute of Standards and Technology, nor is it intended to imply that the entities, materials, or equipment are necessarily the best available for the purpose.

National Institute of Standards and Technology Technical Note 1722 Natl. Inst. Stand. Technol. Tech. Note 1722, 44 pages (February 2013) http://dx.doi.org/10.6028/NIST.TN.1722

CODEN: NTNOEF 


\section{Contents}

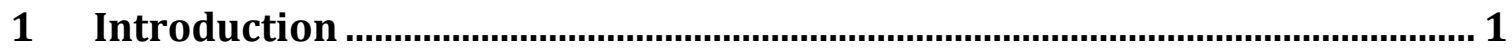

2 Overview of the Egress Estimator Model.......................................................... 3

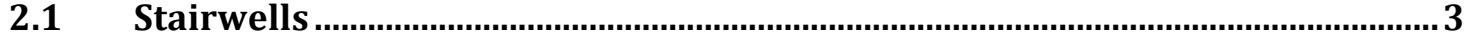

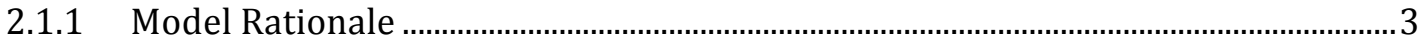

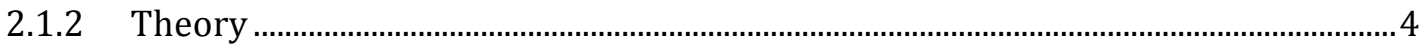

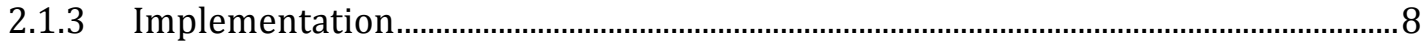

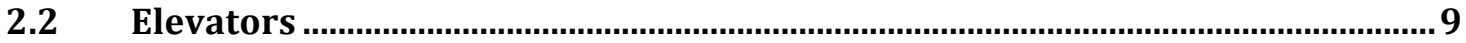

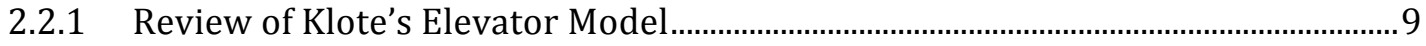

2.2.2 Assumptions and Implementation .......................................................................13

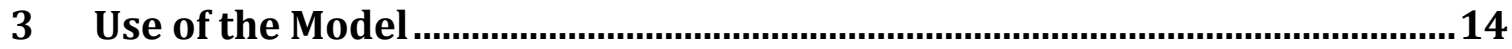

3.1 Introduction ........................................................................................ 14

3.2 Building and Population................................................................................. 14

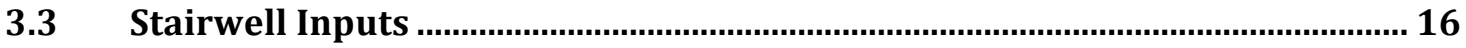

3.4 Elevator Inputs ........................................................................................ 18

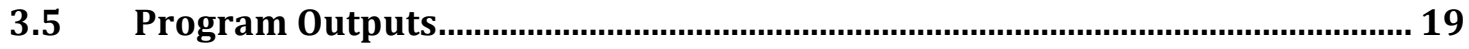

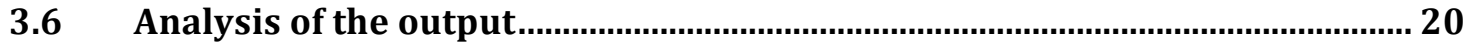

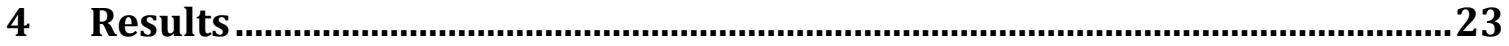

4.1 IMO Criteria ........................................................................................... 23

4.2 Comparison with empirical correlations for stair movement...........................24

4.3 Comparison with ELVAC Calculations............................................................... 29

4.4 Comparison with Evacuation Drill Data ........................................................... 30

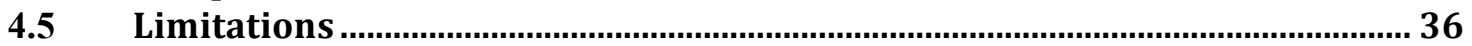

5 Conclusion

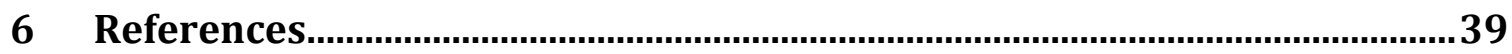




\section{Figures and Tables}

Figure 1. Evacuee speed on stairwells as a function of stairwell angle. Data from Table 1 taken from reference [6] ..............................................................................

Figure 2. Estimated egress time in an arbitrary building configuration for different building heights and solver time steps..................................................................

Figure 3. Stair 8 North data with the prediction of Egress Estimator and twice the

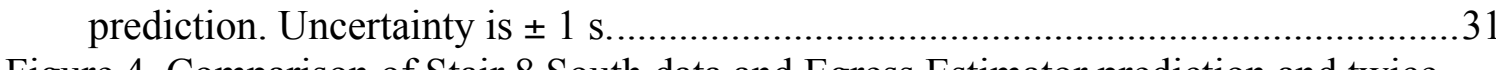

Figure 4. Comparison of Stair 8 South data and Egress Estimator prediction and twice prediction. Uncertainty is $\pm 1 \mathrm{~s}$...........................................................................

Figure 5. Comparison of Stair 8 South data and Egress Estimator prediction and twice

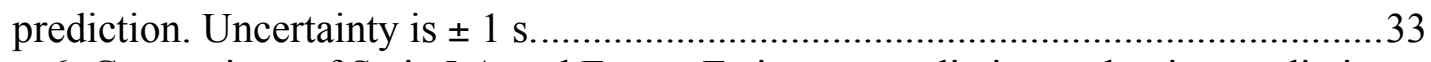

Figure 6. Comparison of Stair $5 \mathrm{~A}$ and Egress Estimator prediction and twice prediction.

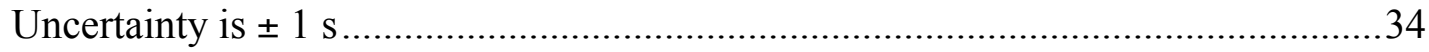

Figure 7. Comparison of Stair $4 \mathrm{~B}$ data and Egress Estimator prediction and twice

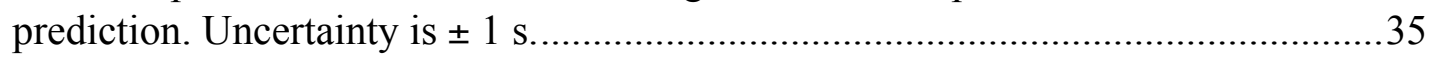

Figure 8. Normalized data from all stairs as compared to predictions of Egress Estimator.

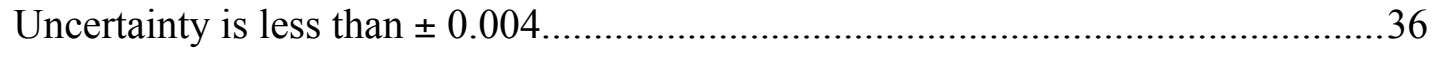

Table 1. Constants for equation (8) for a range of geometries. Data from reference [6]...6 Table 2. Summary of comparison of egress data with Egress Estimator predictions ........35 


\title{
Simple Estimates of Combined Stairwell / Elevator Egress in Buildings
}

\author{
Paul A. Reneke, Richard D. Peacock, and Bryan L. Hoskins \\ Engineering Laboratory \\ National Institute of Standards and Technology
}

\section{Introduction}

The U.S. General Service Administration (GSA) manages thousands of federal properties, the design and construction of new buildings and the renovation of existing ones. One aspect of this mission is determining what fire safety and life safety systems to include in construction or renovation projects. While GSA generally meets or exceeds local building standards in a cost-effective way, the lack of quality research data makes it very difficult to determine the performance of current or new systems. To address this problem the GSA has funded the Engineering Laboratory (EL) of the National Institute of Standards and Technology (NIST) to develop performance requirements and data suitable to support the design and acceptance of cost-effective elevator and stairwell systems that provide for efficient and timely evacuation of occupants including those with disabilities, and that facilitate more efficient fire department operations.

Approximately $\$ 63$ billion annually is spent on fire protection features in building construction with life safety being a primary concern [1]. A major component of life safety of a building is the ability to evacuate part or all of a building when an emergency occurs. Historically, requirements for fire safety in general and for stairwell egress in particular have evolved in response to large loss fire incidents. Currently, egress systems are designed around an antiquated concept of providing stair capacity for the largest occupant load floor in the building with little or no consideration of occupant behavior, needs of emergency responders, or evolving technologies. NIST has had a leading role in providing a scientific basis for code requirements since the early 1900s. For example, design requirements for stairs, along with the now-ubiquitous $1.2 \mathrm{~m}$ (44 in) stair width, were documented in 1935 by the National Bureau of Standards (NBS, now NIST) report Design and Construction of Building Exits [2]. The landmark 1935 NBS report substantiates recommendations for exit system design based on surveys distributed to practicing architects, field inspections, citations to previous investigations as far back as 1909 , as well as simple observations of exits and exit component usage during rush-hour and fire drill evacuation conditions for contemporary building designs. These recommendations constitute the primary basis for current egress requirements, though modifications have resulted from large-loss incidents, as well as subsequent research.

Science-based egress designs have significant potential to mitigate the growing costs of fire protection features in building construction. Further, about one-fourth of fire victims perish during evacuation, which suggests that there are opportunities to save lives through egress design improvements. Adoption of efficient egress designs and advanced egress technologies can therefore have an impact the life loss due to fire. For example, 
improvements in signage, markings, and lighting led to great reductions in egress time from One World Trade Center on September 11, 2001 compared to the 1993 bombing of the same building. On September 11, 2001, the use of elevators in World Trade Center Building Two (before it was struck by an airplane) led to thousands of lives being saved.

Interest in estimating occupant movement during evacuation is not new. The 1935 NBS report [2] included empirical correlations for movement speed based on stairwell configuration. Over the years, numerous researchers have developed other correlations based on experimental data to predict movement speeds during building evacuations [37] and others have developed computer-based evacuation models that vary widely in application and complexity [8]. All of these are intended to provide building designers and engineers with the ability to develop efficient egress designs to meet building code requirements.

Like stairwell provisions, the use of elevators during fire emergencies was considered as well. As early as 1914, properly protected elevators were seen as essential in taller buildings, but automatic elevators were deemed unsuitable in the 1935 NBS report [2]. More recently, there has been considerable attention to the use of elevators to speed up building evacuation. This included studies of the feasibility of elevator evacuation, human behavior, and the use of elevator lobbies as areas of refuge [9]. Protection from heat, flame, smoke, water, overheating of machinery, and loss of electrical power were seen as important to elevator design [9]. Using model calculations for example buildings, elevator evacuation was estimated to speed evacuation by $16 \%$ to $25 \%$ compared to evacuation by stairs alone; the taller the building the greater the impact.

This report describes a simple tool that combines estimates of stairwell and elevator egress timing to provide an overall estimate of evacuation from buildings. It is based on methods developed in the Society for Fire Protection Engineers (SFPE) Handbook [6] for egress using stairwells and the work of Klote and Alvord [10] on modeling elevator evacuations. First, the theory underlying the use of stairs and elevators will be described. Next, a description of how to use the model will be given. Finally, some results of the model will be examined and compared to available experimental data. 


\section{Overview of the Egress Estimator Model}

In examining the calculations in the Egress Estimator, it is important to understand the problem being solved. The Egress Estimator is envisioned as a screening tool that would be used early as part of the design process to help establish broad design criteria for a building design rather than for a detailed analysis of the performance of a final design.

The Egress Estimator calculates a reference time that can be thought of as an expected time to complete evacuation. While it is becoming increasingly clear that the evacuation of a building is best described with a distribution of times [11] in determining the impact of changes in design criteria a single value such as average time or median are often easier to work with.

The Egress Estimator consists of two sub-models: a model for evacuation using stairs and one for evacuation via elevators. Egress times for the two models are calculated separately but synchronized in simulation time and the maximum of the two times is taken as the overall egress time.

The two models are described in the following sections. First the model of stairwell evacuation will be discussed, including theory and implementation. Then the elevator model will be detailed, including a brief review of the Klote model [10] and its implementation.

\subsection{Stairwells}

The stairwell evacuation sub-model uses a simplified egress calculation based on algorithms published in Chapter 3-14 of the SFPE Handbook [6]. The population assigned to a particular stairwell starts in a single room. This compartment is connected to a single corridor of a given length (the Handbook uses the maximum path length, which ends at the door to the stairwell). Every floor connects to the stairwell, which leads down an exit corridor and finally an exit door. The next three sections describe the logic for the model used, the theoretical development and implementation.

\subsubsection{Model Rationale}

Since the model is to serve as a screening tool rather than validating a final design, it is appropriate to include as input averages to account for specific evacuee traits. Individual and group dynamics such as individual occupant speeds and behaviors, individual or group decisions, and the impact of environmental conditions are not included in this simple tool.

It is also clear from observations of actual evacuations, that movement in corridors and stairways is limited primarily by physical rather than behavioral constraints (in crowded situations at exit doors or in the stairwell when capacity reaches maximum). Since this model is meant as a screening tool, the building population is assumed to have a single, "average," set of behavioral characteristics (such as a delay in beginning to evacuate, speed in corridors and on stairs, and merging behavior entering the stairwells) so that differences in evacuation times are based on the design parameters of the building and their impact on the averaged occupant characteristics. 
This "average" behavior is modeled as a fluid using two state variables, density and speed, to track the evacuation. The density equation accounts for physical constraints in the evacuation and the tracking of evacuees. Conversely, the speed equation represents the human behavior aspect of the problem. In such a simple model, human behavior is limited. Each evacuee is assumed to begin to evacuate at the same time, an individual slows down or speeds up as the people ahead slow down or speed up, and finally if the space ahead of an occupant is full, the speed goes to zero.

\subsubsection{Theory}

The stairwell evacuation is modeled as a $1 \mathrm{D}$ problem with two state variables, $D$ for density and $s$ for speed. Density and speed are assumed to be the same throughout a cell with area $W \Delta x$, where $W$ is width of the cell and $\Delta x$ is the length of the cell. Note that depending on the dimensions of $W$ and $\Delta x$ a cell can hold more than one person.

To find the partial differential equation for density start with the equation for a change in the number of people in a cell, which is simply

$$
\Delta P=P_{\text {in }}-P_{\text {out }}
$$

where $\Delta P$ is the change in the number of people, $P_{\text {in }}$ is the number of people that enter the cell and $P_{\text {out }}$ is the number of people that exit the cell. We can redefine the number of people so that

$$
\begin{aligned}
& \Delta P=\Delta D W \Delta x \\
& P_{i}=f_{i} \Delta t \\
& f_{i}=D_{i} s_{i} w_{i}
\end{aligned}
$$

where $\Delta D$ is the change in density, $f$ is the flow, $\Delta t$ is the change in time and the subscript $i=$ in or out. Substituting into the first equation gives

$$
\Delta D W \Delta x=f_{\text {in }} \Delta t-f_{\text {out }} \Delta t
$$

Dividing both sides by $\Delta W \Delta x \Delta t$ and group gives

$$
\begin{aligned}
& \frac{\Delta D}{\Delta t}=\frac{f_{\text {in }}-f_{\text {out }}}{W \Delta x}=-\frac{1}{W} \frac{\Delta f}{\Delta x} \\
& \Delta f=f_{\text {out }}-f_{\text {in }}
\end{aligned}
$$

Taking the limit as $\Delta D, \Delta f, \Delta t$ and $\Delta x$ go to 0 gives the partial differential equation

$$
\dot{D}=-\frac{1}{W} \frac{\partial f}{\partial x}
$$


Because $f_{i}=D_{i} s_{i} w_{i}$ we can simplify the derivative even further to an equation only dependent on that state variables

$$
\dot{D}=-\frac{w}{W}\left[s \frac{\partial D}{\partial x}+D \frac{\partial s}{\partial x}+\frac{D s}{w} \frac{\partial w}{\partial x}\right]
$$

If the width of the entry and exit of a cell are the same and equal to the width of the cell the equation further simplifies to

$$
\dot{D}=-\left(s \frac{\partial D}{\partial x}+D \frac{\partial s}{\partial x}\right)
$$

In stairs, the width of the cell is defined as the full width of the stairs less a boundary layer on each side to account for handrails and the fact that evacuees leave space near the sides of the stairs. On stairs and landings, this boundary layer is taken to be $0.15 \mathrm{~m}$ [6]. According to Hoskins et al [7], it is important to include only the space evacuees actually use in calculation of landing density. The egress estimator calculates landing density with the following method from [7]. The path length is given by

$$
l_{l}=\frac{\pi w_{s}^{2}}{2}+l_{g}
$$

where $l_{l}$ is the travel length on the landing, $w_{s}$ is the width of the stair and $l_{g}$ is the length of the gap between the two stairs. The path assumes that evacuees travel in an arc and use a semi-circle plus the length of the gap, which is assumed to be $0.1 \mathrm{~m}$.

The area on the landing that is used by the evacuees is calculated assuming the same arc path and is essentially half a doughnut with the hole defined by the boundary layer, $b_{s}$. The equation for the area, $A_{l}$, is given by

$$
A_{l}=\frac{\pi}{2}\left[\left(w_{s}-b_{s}\right)^{1 / 2}-b_{s}^{2}\right]+l_{g}\left(w_{s}-2 b_{s}\right)
$$

The effective width used for the landing cells is simply the area divided by the travel path given as

$$
w_{l}=\frac{A_{l}}{l_{l}}
$$

where $w_{l}$ is the effective width of the landing area.

There is one other issue with the geometry used in the Egress Estimator. In previous estimates [12] stair density is calculated using only horizontal stair tread depth. Other publications do not indicate how the calculation is made. The ratio between travel distance and length used for density on a flight of stairs is 


$$
\begin{aligned}
n_{s}\left(w_{s}-2 b_{s}\right) r\left(l_{t}^{2}+l_{r}^{2}\right)^{1 / 2} & =n_{s}\left(w_{s}-2 b_{s}\right) l_{t} \\
r & =\left(\frac{l_{t}^{2}}{l_{t}^{2}+l_{r}^{2}}\right)^{1 / 2}
\end{aligned}
$$

where $n_{s}$ is the number of stairs, $l_{t}$ is the depth of the tread and $l_{r}$ is the height of the riser. The egress estimator uses the ratio to adjust the area and speed used in the density equation. The ratio is used wherever the density on the stairs multiplies a unit of length in the direction of travel on the stairs. Consider the case of the cell at a top of a flight of stairs where the flow of evacuees is coming from the landing. The equation would be

$$
\dot{D}=-\frac{D_{i} s_{i} w_{i}-D_{o} r s_{o} w_{o}}{W_{o} r \Delta x}
$$

where the $i$ subscript designates values from the landing cell and the $o$ subscript is for values coming from the cell at the top of the flight of stairs. Note that this only impacts the density equation for the cell at the top of a flight of stairs and the first cell of the landing at the bottom of a flight of stairs; the ratio cancels out for interior stair cells.

The SFPE Handbook gives the following equation relating speed $(\mathrm{m} / \mathrm{s})$ to density (person $/ \mathrm{m}^{2}$ ) for density $D$ greater than 0.54 people $/ \mathrm{m}^{2}$.

$$
s_{s p p e}(D)=k-a k D
$$

\begin{tabular}{|c|c|c|c|}
\hline \multicolumn{2}{|c|}{ Exit route element } & $\begin{array}{c}K \\
(\mathrm{~m} / \mathrm{s}) \\
\end{array}$ & $\begin{array}{c}s_{s f p e}(0.54) \\
(\mathrm{m} / \mathrm{s}) \\
\end{array}$ \\
\hline \multicolumn{2}{|c|}{ Corridor, isle, ramp or doorway } & 1.40 & 1.20 \\
\hline Stairs, Riser (in) & Stairs, Tread (in) & & \\
\hline 7.5 & 10 & 1.00 & 0.86 \\
\hline 7.0 & 11 & 1.08 & 0.92 \\
\hline 6.5 & 12 & 1.16 & 0.99 \\
\hline 6.5 & 13 & 1.23 & 1.05 \\
\hline
\end{tabular}

with $a=0.266$ and $k(\mathrm{~m} / \mathrm{s})$ given in Table 1 .

Table 1. Constants for equation (8) for a range of geometries. Data from reference [6].

For density, $D$, less than 0.54 people $/ \mathrm{m}^{2}$, the speed, $s$, is equal to $s_{s f p e}(0.54)$ as shown in Table 1.

We will assume that people's speed doesn't change instantly but approaches the ideal speed given by the Handbook equation. Furthermore we assume that people don't adjust their speed based on the conditions around them but just based on the conditions ahead of them. This gives the equation 


$$
\dot{s}_{j}=a\left(s_{s f p e}\left(D_{j+1}\right)-s_{j}\right)
$$

where $a$ is a parameter determining how quickly speed changes, $s_{j}$ is the speed in the $j^{\text {th }}$ cell and $D_{j+1}$ is the density in the next cell in the direction of egress.

The SFPE Handbook [6] includes values for four stair configurations and a flat surface (see Table 1). To be more general, it is desirable to allow a continuous range of stair configurations. The first step is to determine a method for calculating the maximum speed (or $k$, since one defines the other) for a general configuration.

The following plot shows the speeds given in the SFPE Handbook against the angle of the stairs. It also shows two fits to the data. One is a linear fit and the other uses a quadratic. Clearly the quadratic fit represents the data and has the better $\mathrm{R}^{2}$. The Egress Estimator determines the maximum speed for a given stair configuration using this quadratic equation.

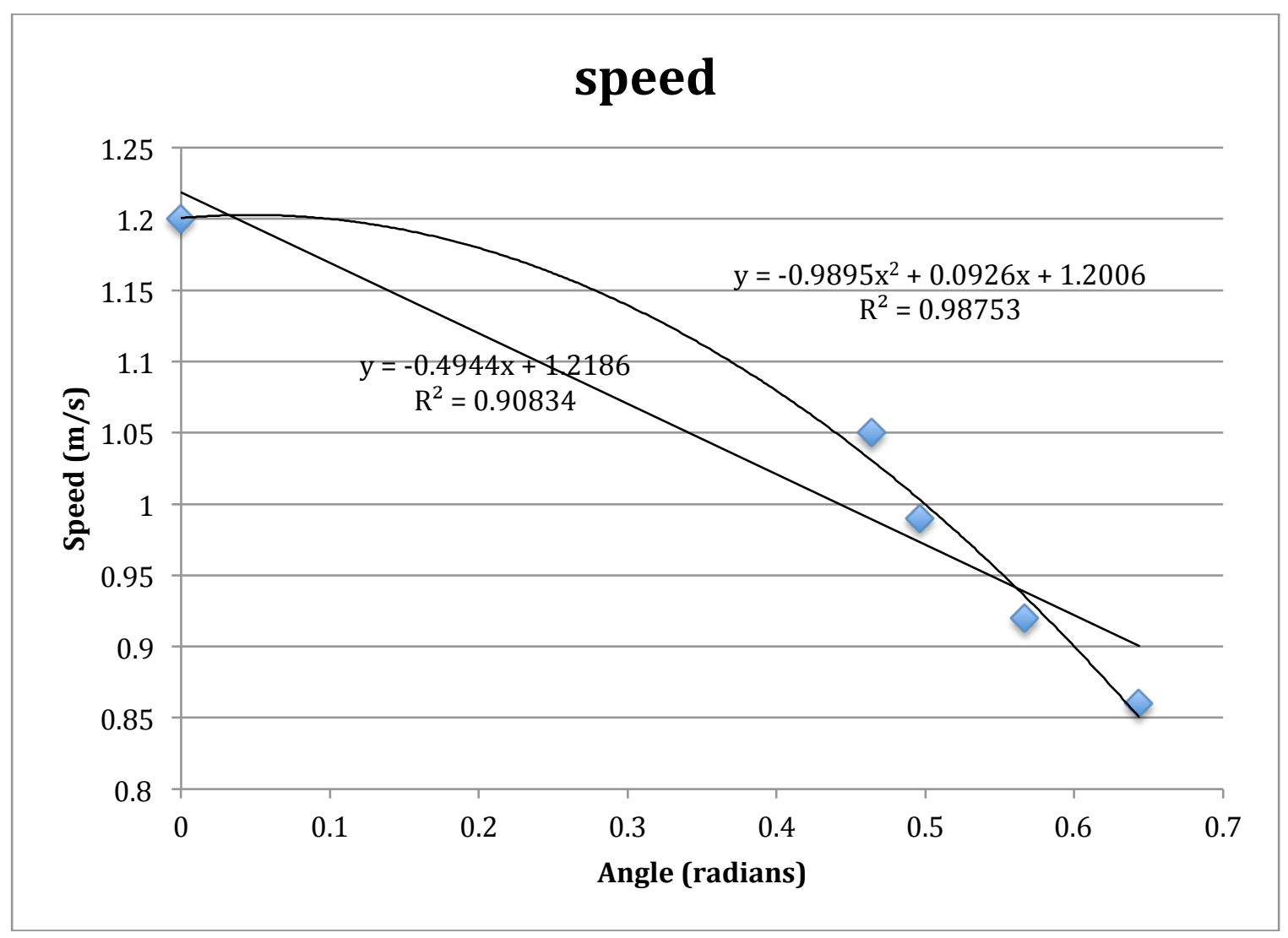

Figure 1. Evacuee speed on stairwells as a function of stairwell angle. Data from Table 1 taken from reference [6]. 
In order to find $k$ used for a given maximum speed, we first reorganize $s_{s f p e}(D)$ so that it is more easily interpreted physically

$$
\begin{aligned}
& s_{s f p e}(D)=(1-a D) k \\
& s_{s f p e}(D)=\frac{D_{\max }-D}{D_{\max }} \hat{s}_{\max }
\end{aligned}
$$

where $\hat{s}=k$ is the pseudo maximum speed. If speed continued to increase for $D<0.54$ then at $D=0$ the speed would be $\hat{s}$. Solving for $\hat{s}$ gives

$$
\hat{s}_{\max }=\frac{D_{\max } s_{\max }}{D_{\max }-D_{\min }}
$$

where $D_{\min }=0.54$. Substituting into $s_{s f p e}(D)$ and (11) yields

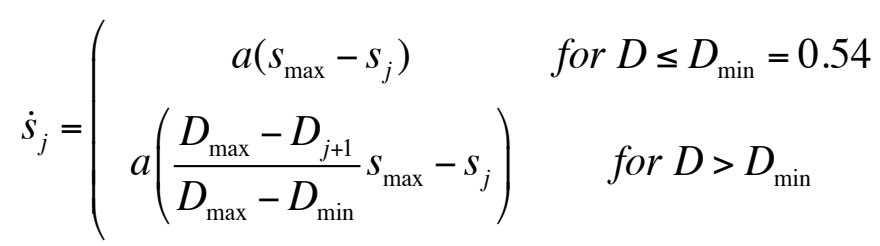

Equations (5) and (12) are the time derivatives for density and speed used in the model.

\subsubsection{Implementation}

The Egress Estimator is a 1-dimensional partial differential equation set that uses an explicit Runga-Kutta solver. To implement the model, the simulation is first broken into different elements: corridors, flights of stairs or landings. Each element has its own parameters including width, length, maximum speed and maximum density. Elements are discretized into cells with widths equal to the element's width and approximately $1 \mathrm{~m}$ in length. There are at least two cells in each element. Because elements can be of any length, for example a corridor could be $43.2 \mathrm{~m}$ in length, the cells are not exactly $1 \mathrm{~m}$ but the program determines the number of cells so the length is as close to $1 \mathrm{~m}$ as possible.

One important issue of an explicit solver is the length of the time step. The longer the time step the faster the model runs but the more error can accumulate reducing the accuracy of the solution. The shorter the time step the less error accumulates but the longer each run of the model takes. In order to establish the time step to use for the model, the estimated egress time for four cases (that differed only in the number of floors in the building) was calculated using time steps $0.05 \mathrm{~s}, 0.1 \mathrm{~s}, 0.2 \mathrm{~s}, 0.3 \mathrm{~s}, 0.4 \mathrm{~s}$ and $0.5 \mathrm{~s}$. Figure 2 shows the percent difference between each run and the run using a time step of $0.2 \mathrm{~s}$. 
For time steps greater than $0.2 \mathrm{~s}$, solver error seems to accumulate, but even the largest error is less than $1.6 \%$. A time step of $0.2 \mathrm{~s}$ was chosen to balance both speed of calculation and limiting accumulating error.

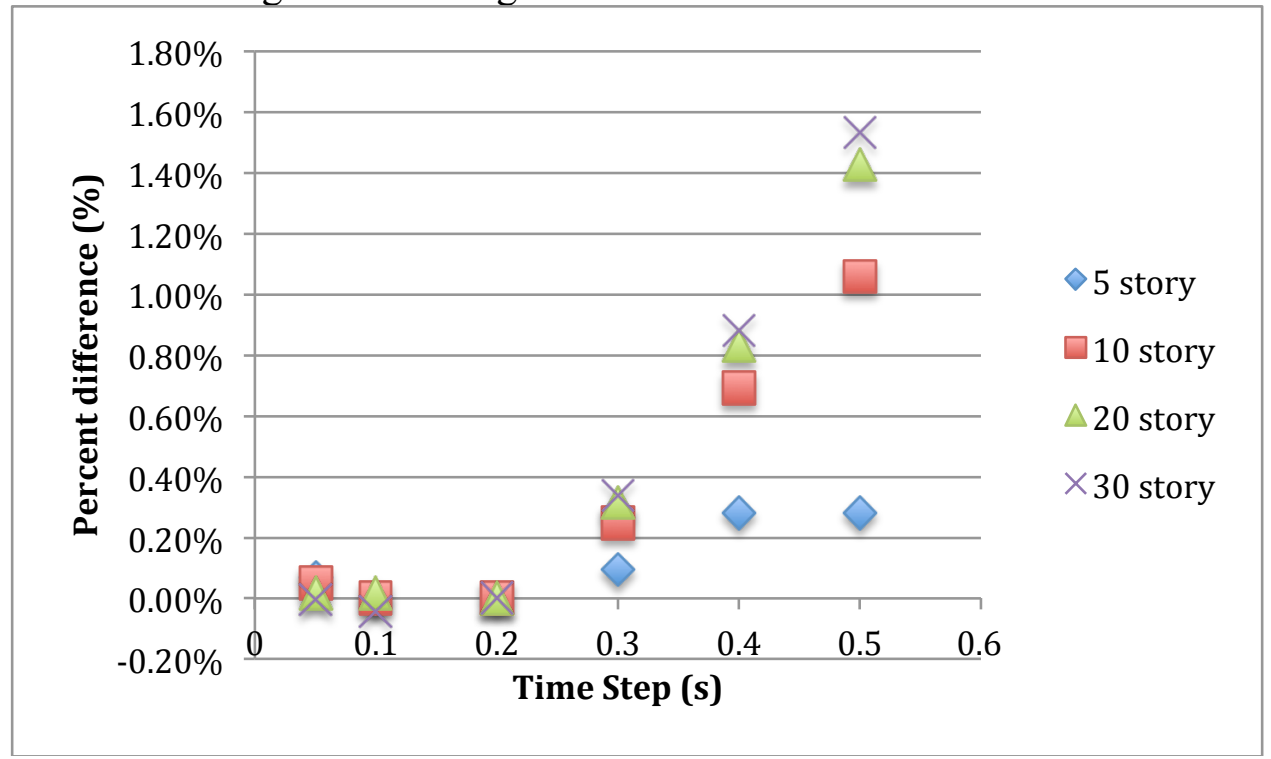

Figure 2. Estimated egress time in an arbitrary building configuration for different building heights and solver time steps.

The density equation used in the model is Eq. (5) rather than (6) since it is operationally simpler. When the entry and exit are the same width as the cell (6) takes only 4 multiplications or divisions it takes 3 additions or subtractions. Eq. (5) takes 5 multiplications or division but only 1 subtraction. However, when the entry or exit width is different from the cell width or the flow of two cells are merging into one cell the implementation of (6) is significantly more difficult than (5).

Because doors can constrain flow not only because of the width, but also due to the use of automatic door closers, which are not considered in the model, the model allows the user to specify a maximum flow rate in order to capture additional effects, if appropriate.

\subsection{Elevators}

The GSA has been interested in the use of elevators in emergency evacuations for many years. In 1992, with GSA support, Klote and Alvord [10] published a model of elevator evacuation, ELVAC. This model serves as the basis for the elevator model included in the current model and so the following sections will review the ELVAC model.

\subsubsection{Review of Klote's Elevator Model}

The ELVAC model starts off with a basic equation that describes the total evacuation time for elevator evacuation 


$$
t_{e}=t_{a}+t_{o}+\frac{1+\eta}{J} \sum_{r=2}^{R} \sum_{j=1}^{m_{r}} t_{r, j}
$$

where $t_{e}$ is the total time for evacuation, $t_{a}$ is the time for elevator cars to be recalled to the first floor, $t_{o}$ is the evacuation time for the $1^{\text {st }}$ floor elevator lobby, $J$ is the number of elevators, $R$ is the number of floors being evacuated, $m_{r}$ is the number of trips it takes to evacuate the $\mathrm{r}^{\text {th }}$ floor, $t_{r, j}$ is the total trip time for the $\mathrm{j}^{\text {th }}$ trip to the $\mathrm{r}^{\text {th }}$ floor and $(1+\eta)$ is the trip inefficiency.

The start up time, $t_{a}$, is a user specified time when all the elevator cars are in the lobby ready to start the evacuation. The evacuation time of the first floor lobby, $t_{o}$, is also a user specified time and represents the amount of time from when the last car unloads in the lobby till everyone has evacuated the building.

The trip time is calculated in the following equation

$$
t_{r, j}=2 t_{t, r}+t_{i}+t_{u}+2 t_{d}
$$

where $t_{t, r}$ is the time it takes to go from the lobby to floor $r$ or vice versa, $t_{i}$ is the time it takes to load the elevator, $t_{u}$ is the time it takes to unload the car and $t_{d}$ is the time it takes to open or close the car doors. As can be seen in the equation for trip time the model makes heavy use of symmetry. Each term in the trip time equation will be discussed separately.

\subsubsection{Travel time}

As a car travels from one floor to another, it can go through as many as 5 phases of acceleration depending on the distance: constant acceleration, transitional acceleration, constant speed or no acceleration, transitional deceleration and constant deceleration. The duration and distance travel in the constant acceleration and deceleration phases are equal as well as in the transitional acceleration and deceleration phases.

The acceleration/deceleration phase ends when a car reaches a certain fraction, $f$, of the normal maximum travel speed, $v_{\max }$. Using Newton's equations of motion for a constant acceleration to find the duration of constant acceleration, $t_{1}$ gives

$$
\begin{aligned}
& f v_{\text {max }}=a t_{1} \\
& t_{1}=\frac{f v_{\text {max }}}{a}
\end{aligned}
$$

with $t_{l}$, the distance traveled, as

$$
\begin{aligned}
& s_{1}=1 / 2 a t_{1}^{2} \\
& s_{1}=\frac{f^{2} v_{\max }^{2}}{2 a}
\end{aligned}
$$


Remembering that it takes the same amount of time and distance to decelerate as accelerate, if the height of $r^{\text {th }}$ floor, $s_{r}$, is less then the distance required to complete the acceleration/deceleration phase, $2 s_{1}$, the car never leaves the constant

acceleration/deceleration phase. The total time, $t_{e}$, is twice the acceleration time, since at the half way point the car starts to decelerate, which gives

$$
\begin{aligned}
& \frac{s_{r}}{2}=\frac{a t_{r}^{2}}{2} \\
& t_{r}=\sqrt{\frac{s_{r}}{a}} \\
& t_{e}=2 t_{r}+t_{\ell}=2 \sqrt{\frac{s_{r}}{a}}+t_{\ell}
\end{aligned}
$$

If $s_{r}>2 s_{1}$ then the car enters the transitional acceleration phase. The transitional acceleration phase is not derived directly but the distance traveled and duration are approximated. The time it takes to go from constant acceleration to constant velocity, delta $t_{2}$, and the total time, $t_{2}$, are given by

$$
\begin{aligned}
& \Delta t_{2}=\frac{v_{\max }^{2}-v_{1}^{2}}{2 v_{1} a} \\
& t_{2}=\Delta t_{2}+t_{1}
\end{aligned}
$$

The distance traveled in the transitional acceleration phase and the total distance traveled after the transitional acceleration phase are given by

$$
\begin{aligned}
& \Delta s_{2}=\frac{1}{3 a}\left(\frac{v_{\max }^{3}}{v_{1}}-v_{1}^{2}\right) \\
& s_{2}=\Delta s_{2}+s_{1}
\end{aligned}
$$

If $s_{1}<s_{r}<s_{2}$ then the velocity, $v_{r}$, at the end of transitional acceleration when transitional deceleration would start is

$$
v_{r}=\left[v_{1}^{3}+3 a v_{1}\left(\frac{s_{r}}{2}-s_{1}\right)\right]^{1 / 3}
$$

The time in the transitional acceleration/deceleration phase and the total time of the trip, $t_{r}$, are given by 


$$
\begin{aligned}
& \Delta t_{r}=\frac{v_{r}^{2}-v_{1}^{2}}{2 a v_{1}} \\
& t_{r}=\Delta t_{r}+t_{1} \\
& t_{e}=2 t_{r}+t_{\ell}
\end{aligned}
$$

If $s_{r}>s_{2}$ then the car travels a certain distance, delta $s_{3}=s_{r}-s_{2}$, at the constant speed, $v_{\max }$. The time the car travels at constant speed and the total time the car travels are

$$
\begin{aligned}
& \Delta t_{3}=\frac{s_{T}-2 s_{2}}{v_{\max }} \\
& t_{e}=\Delta t_{3}+2 t_{2}+t_{\ell}
\end{aligned}
$$

where $t_{1}$ is the leveling time. The leveling time is the time the car takes to make final adjustments to line up with the arrival floor and it is assumed to be 0.5 s. [9]

\subsubsection{Standing Time}

The standing time, $t_{s}$, is the time it takes to load passengers on the evacuation floor, $t_{i}$, and unload them on the exit floor, $t_{u}$, plus the time it takes to open and close the doors twice, $t_{d}$. The equation is

$$
t_{s}=\left(t_{i}+t_{u}+2 t_{d}\right)(1+\mu)
$$

where, $\mu$, is the transfer inefficiency, which is defined as

$$
\mu=\alpha+\varepsilon+\gamma
$$

where $\alpha$ is basic transfer inefficiency taken here as $0.1, \varepsilon$ takes into account populations that have significant mobility challenges. In this model, $\varepsilon$ is 0.0 , representative of a normally mobile population, and $\gamma$ which is the variance from a standard $1200 \mathrm{~mm}$ (48 in) door. Values for gamma come from table 1 of the Appendix of Klote [10]. Opening and closing times are taken from the same table.

Loading and unloading times have the same form but differ in coefficients. There is a minimum time that the elevator doors are open. This is the time it takes to load 2 people. For more than 2 people there is a rate, which is different for loading and unloading. The equation is

$$
t_{s}=\left\{\begin{array}{cc}
t_{d w} & \text { for } N \leq 2 \\
t_{d w}+t_{\text {in/out }}(N-2) & \text { for } N>2
\end{array}\right.
$$


where $t_{d w}$ is the dwell time or minimum time the door remains open and is $4.0 \mathrm{~s}, t_{\text {in/out }}$ is the rate that people load or unload a car with the loading rate equal to 1.0 person/s and the unloading rate equal to $0.6 \mathrm{person} / \mathrm{s}$.

\subsubsection{Assumptions and Implementation}

The above description is of the model of elevator evacuation that has been previously developed in ELVAC [10]. There is one significant difference between the original ELVAC model and the one included in the Egress Estimator. Instead of using assuming a trip inefficiency as in Eq. (18), the current model implements a simple elevator control algorithm to allow more flexibility. This was done for two reasons. The first was so that elevator evacuation could be tracked along with the stair evacuation for output. The second is that including an elevator control algorithm makes it possible to test alternative algorithms and layouts of elevators not included in the original ELVAC model. For example, the original ELVAC model assumed that evacuation proceeded in a single bank of elevators operating in unison beginning at the highest occupied floor in the building.

The elevator control algorithm is simple and based on call signals from occupied floors. At the beginning of the evacuation the cars are given an initial order with the first car going to the highest floor, the next car to the next highest floor, and so on. When a car on the ground floor is assigned a destination floor, that floor's call signal is stopped so that the next available car will not go to that floor until the originally assigned car has loaded and left the floor. If any occupants remain on the floor, another call is activated and the process starts anew. Once a car has returned to the ground floor and unloaded its passengers, it is assigned the highest floor that has a call signal and repeats the process.

Towards the end of an evacuation the situation can arise that there are more elevator cars than occupied floors. When this happens, a car can be on the ground floor and finished unloading but all the occupied floors have cars assigned to them. The car then waits at the ground floor until an occupied floor call is activated. While this is typical of Phase I recall requirements in the model codes, other more sophisticated algorithms are certainly possible.

The model assumes that everyone that is using the elevators is in the elevator lobby when the elevators start the evacuation mode. The second assumption is that once an elevator car has loaded and left a floor, any remaining people will press the call button to get the next available car.

The implementation is straightforward. A single round trip is made up of four events: traveling to the call floor, loading passengers and closing the doors, traveling to the ground floor, and unloading passengers. For each car, the time until the next event is calculated and put in its appropriate position in an ordered queue. The queue is ordered so that the first event off the queue is the next event (a first-in, first-out queue). The next event is then taken off the queue and when the simulation reaches that time, the event is said to be complete and the time to the next event is calculated. 


\section{Use of the Model}

\subsection{Introduction}

This section describes the user interface and required inputs. The program uses a single window (below) for both inputs and calculated egress time output. This software tool is intended to help the user estimate the time that would be required for building evacuation by stairs, elevators, or a combination of both. While the tool considers occupant loading, the capacity and number of stairs and elevators in a building, the details of occupant behavior, environmental effects, or damage due to an emergency event, and other potentially important events are not included. If more detailed analyses are needed, other simulation tools should be employed (for examples see [13]).

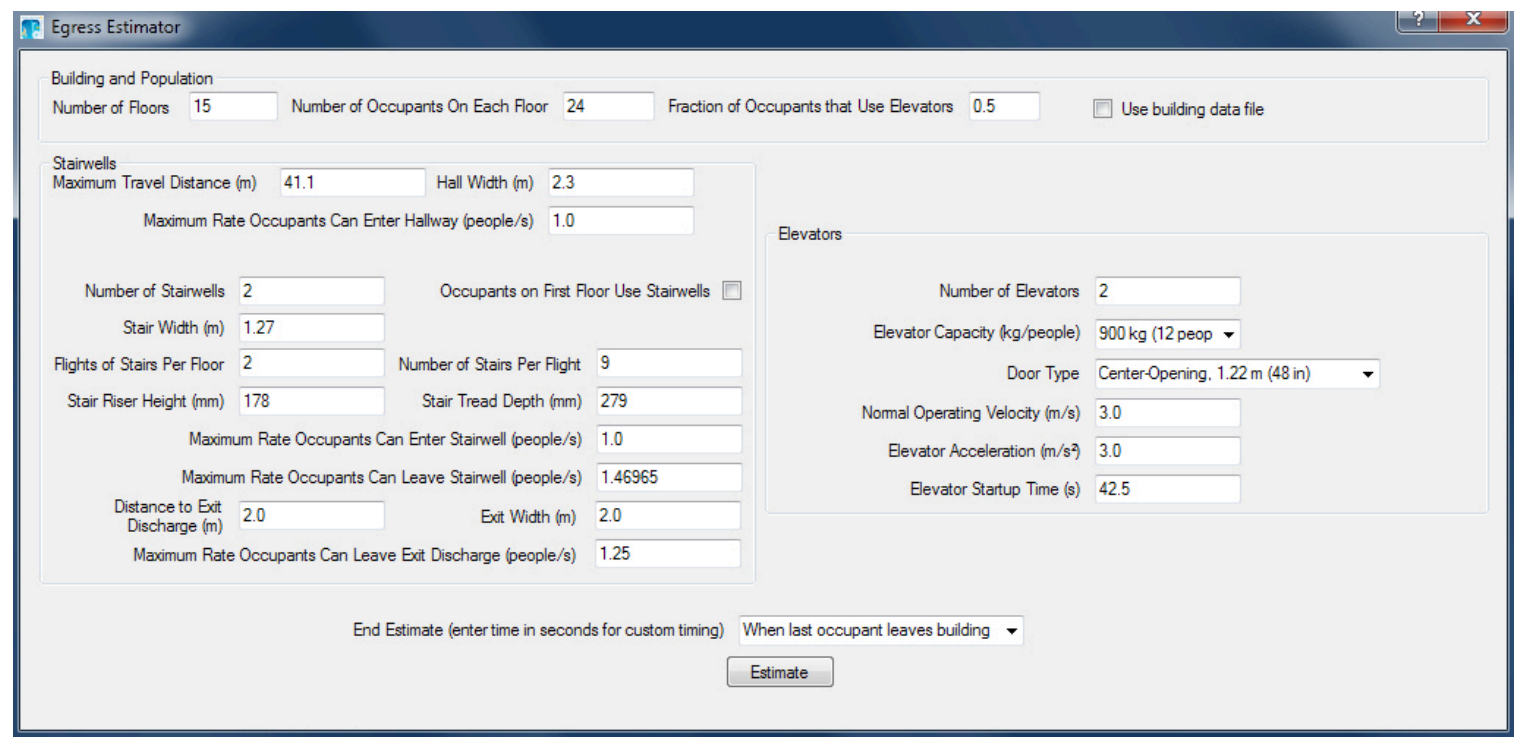

The program input is divided into several areas that allow the user to define details of building occupants, stairwells, elevators, and exits.

\subsection{File Menu}

At the top of the window the Egress Estimator has a single menu item, File. Clicking on File drops down three sub menu items: New, Open, and Save. Clicking on New resets all the fields to the default conditions. Open allows the user to select an Egress Estimator output file or saved file to set the initial conditions. Save allows the user to save the current initial conditions to a file without having to run a full simulation.

\subsection{Building and Population}

$\begin{aligned} & \text { Building and Population } \\ & \text { Number of Floors }\end{aligned} \quad \begin{array}{lllll} & \text { Number of Occupants On Each Floor } 24 & \text { Fraction of Occupants that Use Elevators } & 0.5 & \square \text { Use building data file }\end{array}$


For the estimates in this tool, the building is defined by the number of floors in the building, the number of occupants on each floor of the building, and the fraction of building occupants who use the elevators during evacuation.

Number of Floors: Input the number of floors in the building, including the exit floor. For the simple estimates in this tool, all floors of the building are assumed to be occupied. If the building includes unoccupied floors with mechanical or other equipment, these would normally not be included in the input. The number or height of stairs in each flight can be adjusted upward to account for the additional height of the unoccupied floors.

Number of Occupants on Each Floor: The average number of occupants on each floor of the building. For the simple estimates in this tool, all floors are assumed to have the same number of occupants.

Fraction of Occupants that Use Elevators: Input the fraction of occupants on each floor that use elevators for evacuation. The remaining population are spread evenly among the stairwells.

Use building data file: If checked, the software will prompt for a comma-delimited spreadsheet file containing floor-specific information. Each line of the spreadsheet specifies the following information for one or more floors:

Starting floor: the lowest floor (inclusive) in the group of floors being specified Ending floor: the highest floor (inclusive) in the group of floors being specified Population: the number occupants on each floor in the group of floors

Fraction using elevators: the fraction of occupant on each floor in the group of floors that use elevators for evacuation.

Starting time for stairwell evacuation: delay time from beginning of evacuation when occupants begin to travel towards the stairwells for evacuation.

Starting time for elevator evacuation: delay time from beginning of evacuation when occupants begin to travel towards the elevators for evacuation.

A sample building data file is shown below. Note that you only need to include floor data that is different from the values already specified in the main input page for Egress Estimator. All other values and floors use the values specified on the main input page.

\begin{tabular}{|c|c|c|c|c|c|}
\hline $\begin{array}{c}\text { Start floor } \\
\text { (inclusive) }\end{array}$ & $\begin{array}{c}\text { End floor } \\
\text { (inclusive) }\end{array}$ & $\begin{array}{c}\text { Population on } \\
\text { floor }\end{array}$ & $\begin{array}{c}\text { Fraction using } \\
\text { elevator }\end{array}$ & $\begin{array}{c}\text { Start of stair } \\
\text { evacuation }\end{array}$ & $\begin{array}{c}\text { Start of elevator } \\
\text { evacuation }\end{array}$ \\
\hline 2 & 2 & 100 & 0 & 0 & 0 \\
\hline 10 & 15 & 30 & 1 & 0 & 0 \\
\hline End & & & & & \\
\hline
\end{tabular}

The first cell of the row after all input is made has to have the word "End" and the program is case sensitive. All information in cells on that row or subsequent rows will be ignored. 


\subsection{Stairwell Inputs}

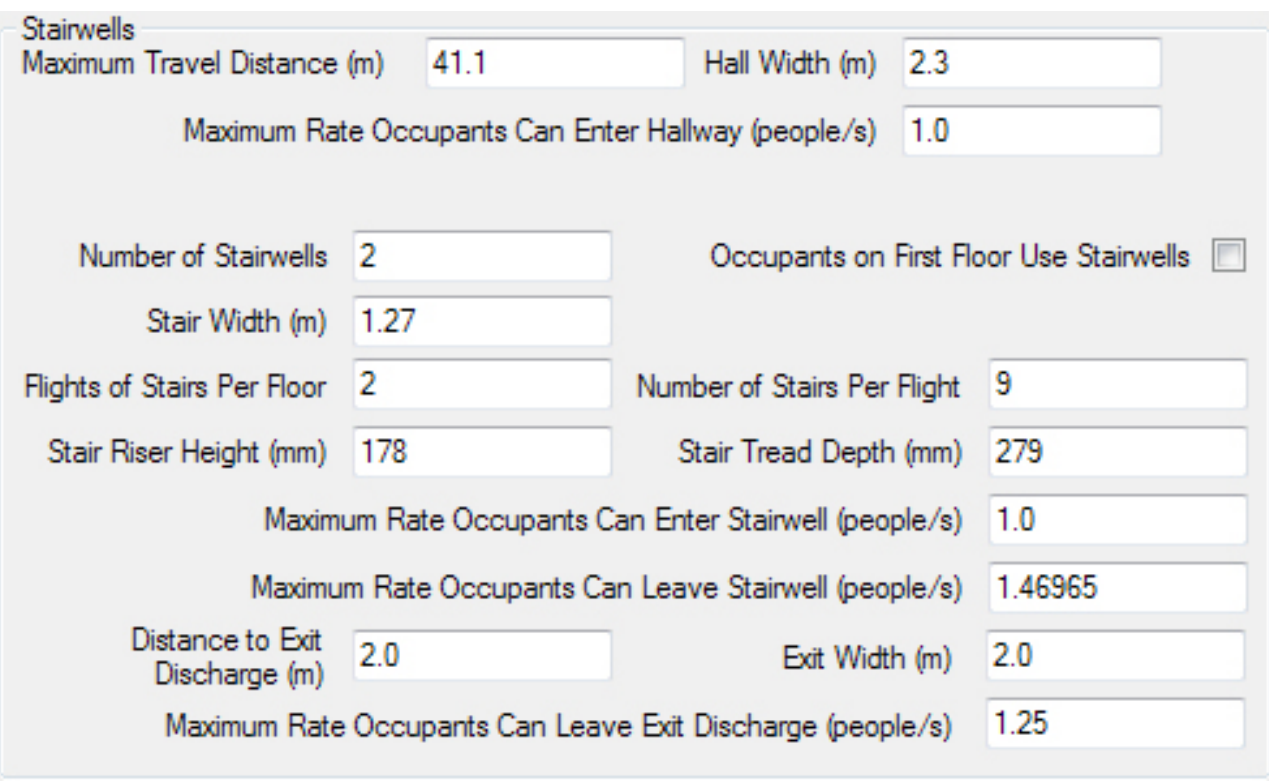

For stairwell evacuation, occupant travel is comprised of travel from a single compartment, from the compartment to a stairwell in a corridor, and down a stairway.

Maximum Travel Distance (m): As a conservative estimate, input the longest distance occupants would have to travel from their starting point to a stairwell for evacuation. For this tool, all corridors (and stairwells) are assumed to be of identical size and configuration.

Hall Width: Input the width of the corridor occupants use to travel from their starting point to the stairwell for evacuation.

Maximum Rate Occupants Can Enter Hallway (people/s): A typical value for flow through a single doorway is 1 person/s [6]. If there are multiple doorways opening onto the corridor or obstructions to entering the corridor, this value may be increased or decreased as appropriate. The SPFE handbook [6] includes additional information on movement speed as a function of width and occupant density.

Number of Stairwells: The number of stairwells in the building that are used for occupant egress. For this tool, all stairwells are identical and are assumed to serve all floors of the building.

Occupants on First Floor Use Stairwells: Check this box if occupants on the exit floor typically use the same egress path as occupant on the stairwells. When checked, occupants from the exit floor merge with occupants from higher floors (see merging options below) as part of the egress calculation.

Stair Width (m): Input the full width of the stairwell. 
Flights of Stairs Per Floor: Input the typical number of flights of stairs from (landing to landing) between floors. For this tool, all flights of stairs are assumed to be identical throughout the building.

Number of Stairs Per Flight: Input the number of stairs in each flight of stairs. For this tool, the number of stairs in each flight is assumed to be the same throughout the building.

Stair Riser Height (mm): Input the height of each stair measured from tread to tread.

Stair Tread Depth (mm): Input the size from front to back of each stair tread.

Maximum Rate Occupants Can Enter Stairwell (people/s): Gwynne et al found that the typical flow rate through a door with a closer is 0.92 people/(m s) [14]. If there are multiple doorways opening onto the stairwell or obstructions to entering the corridor, this value may be increased or decreased as appropriate. The SPFE Handbook [6] includes additional information on movement speed as a function of width and occupant density.

Maximum Rate Occupants Can Leave Stairwell (people/s): Gwynne et al found that the typical flow rate through a door with a closer is 0.92 people $/(\mathrm{m} \mathrm{s})$ [14]. If there are multiple doorways opening from the stairwell or obstructions when leaving the corridor, this value may be increased or decreased as appropriate. The SPFE handbook [6] includes additional information on movement speed as a function of width and occupant density.

Distance to Exit Discharge (m): Input the length of the exit corridor from the stairs to the building exit or another point of safety.

Exit Width (m): Input the width of the exit from the stairs.

Maximum Rate Occupants Can Leave Exit Discharge (people/s): A typical value for flow through a single doorway is 1 person/s. If there are multiple doorways opening onto the corridor or obstructions to entering the corridor, this value may be increased or decreased as appropriate. The SPFE handbook [6] includes additional information on movement speed as a function of width and occupant density. 


\subsection{Elevator Inputs}

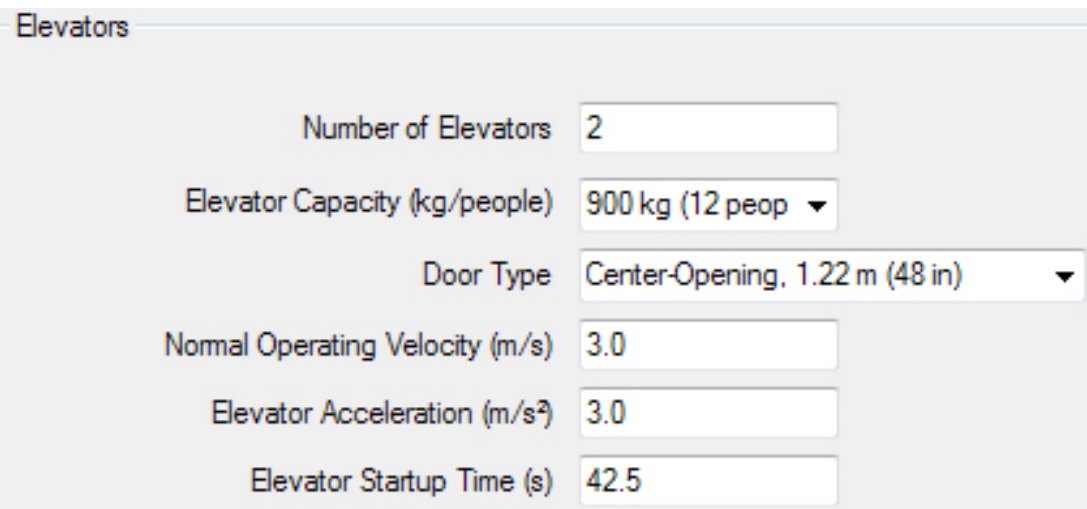

For elevator evacuation, occupant travel is defined by the capacity of the elevators and the travel speed of the elevator. For this tool, elevator evacuation is assumed to proceed as follows: Elevators initially travel to the discharge floor. Once the elevators reach the discharge floor, evacuation begins with the highest occupied floor. Once the highest floor is completely evacuated to the discharge floor, evacuation proceeds with the next highest occupied floor and continues until the entire occupant population is evacuated. It is assumed that the same fraction of occupants on all floors use the elevator for evacuation. In practice, it is likely that some occupants on the lower floors will use the stairs. If a more detailed analysis is required, more complex evacuation models are available [13].

Number of Elevators: Input the number of elevators used for occupant evacuation. For this tool, all elevators in the building are assumed to be identical and operate as a group during evacuation. This assumption will tend to slightly overestimate the time required for elevator evacuation.

Elevator Capacity (kg/people): Input the maximum number of people that can use each elevator car.

Door Type: Select from a range of elevator door types and widths. This input impacts the door opening and closing times for each elevator car at the beginning and end of each trip.

Normal Operating Velocity (m/s): Input the normal full operating velocity of the elevator car. The default in the model uses is a typical value of $3.0 \mathrm{~m} / \mathrm{s}[10]$.

Elevator Acceleration $\left(\mathbf{m} / \mathbf{s}^{2}\right)$ : Elevator motion starts with constant acceleration, followed by a transitional acceleration until constant velocity motion at the normal operating velocity is attained. Input the constant acceleration. Transitional acceleration is calculated by the software. The default value the model uses is $3.0 \mathrm{~m} / \mathrm{s}^{2}[10]$.

Elevator Startup Time (s): The time from activation of the alarms (for example) to the start of the round trips that evacuate people. Input the time spent before the actual 
evacuation by elevator cars begins. Most typically, it is computed to be the time required to bring a fully loaded elevator car from the most distant floor to the discharge floor. If this is not satisfactory, a larger or smaller value may be used.

If the elevators are operated automatically during evacuation, one starts the elevator evacuation after all of the elevators have been moved to the discharge floor and anyone in the elevators have left the elevators. In the case of manual elevator operation, the time for elevator operators to reach the cars must be included.

\subsection{Program Outputs}

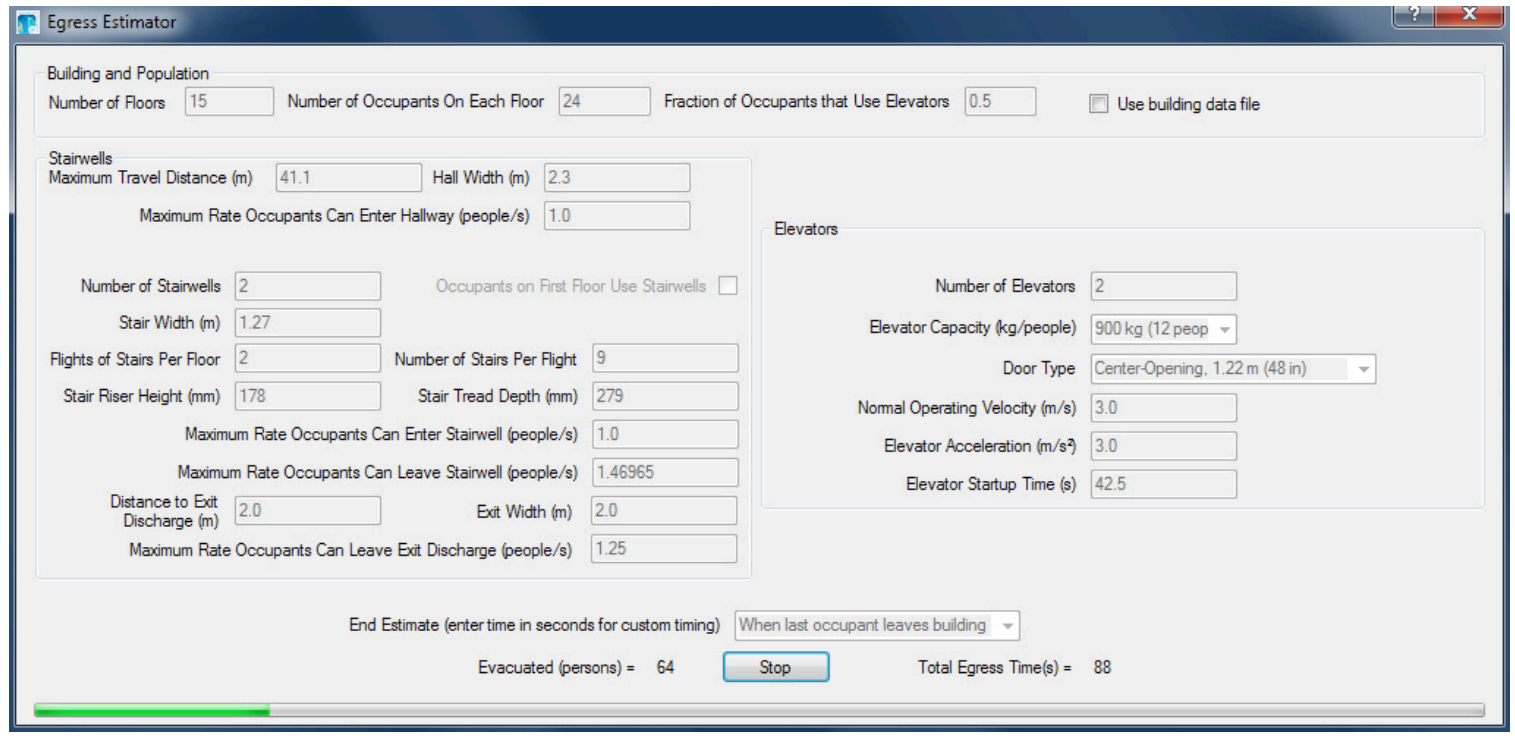

Once appropriate inputs for the building are input to the software, the "Estimate" button begins calculation of occupant egress from the building. The user is prompted for a filename and location to store the results of the calculation (as a comma delimited file that can be read into most spreadsheet programs for further analysis or display.

During the simulation, the number of occupants evacuated and the evacuation time is displayed. When the calculation is complete, the total number of occupants and total evacuation time is shown.

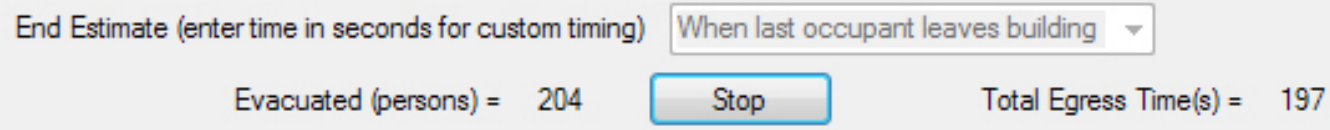

Detailed information on occupant location throughout the evacuation is available in the comma-separated spreadsheet file created during the simulation. 


\subsection{Analysis of the output}

As the Egress Estimator produces extensive sets of data an additional prototype tool was developed to facilitate the analysis and visualization of the output data. This tool was created as a VBA enhanced Microsoft Excel 2007 Workbook. It is available together with Egress Estimator and the file is named EgressVisualization.xlsm. As the EgressVisualization is currently utilizing the VBA macro technology it is necessary to enable macros upon opening the workbook. Unfortunately the tool will most probably not work properly on earlier versions of Excel due to smaller number of columns allowed in previous versions.

EgressVisualization consists of two main screens allowing for a quick overview of output data without the need to manually process the output CSV files.

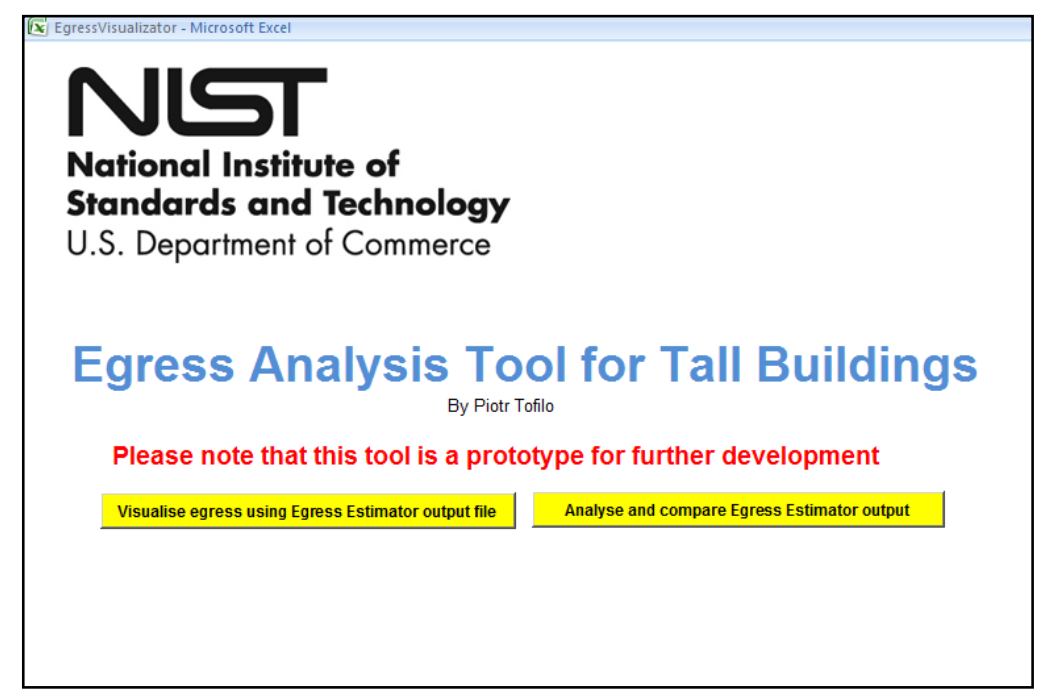

The first screen allows for interactive time based visualization of egress progress. This can happen after pressing the button at the top of the screen "Load file to visualize egress" and loading up the selected CSV file using the standard file dialog. After loading the output file, the user can track the egress progress in the simulated building by using the egress time scroll bar at the top of the screen. The time based egress situation is presented on the five graphs depicting respectively: approximate position of elevators at a given time, number of people still in the elevator lobbies, number of people in each stair, hall/corridor and initial room (numbers of people are represented by green bars). The colors of bars representing the number of people in the stairs can additionally adjusted to represent flow density according to the width of the stair (the stair width has to be adjusted manually at the top of the screen). The last graph presents the overall egress history in the building and the indication of the current time represented by a purple vertical line. By interactively changing the time, the user has the ability to observe the elevator and stair system operation and to establish times when a given egress component (elevator lobby, stair, hall/corridor or room) is empty. With reasonable computing power, 
dragging the scroll bar or pressing and holding the buttons at either end of the scroll can reproduce the dynamics of the egress system quite smoothly.

The following pictures present screenshots from the EgressVisualization after loading output data from EgressEstimator for an example test case that was run for a 30-floor building. First screenshot shows initial situation at time $=0$ and the second screen shows the situation at an arbitrary time selected by the user with the slider on the time scroll.
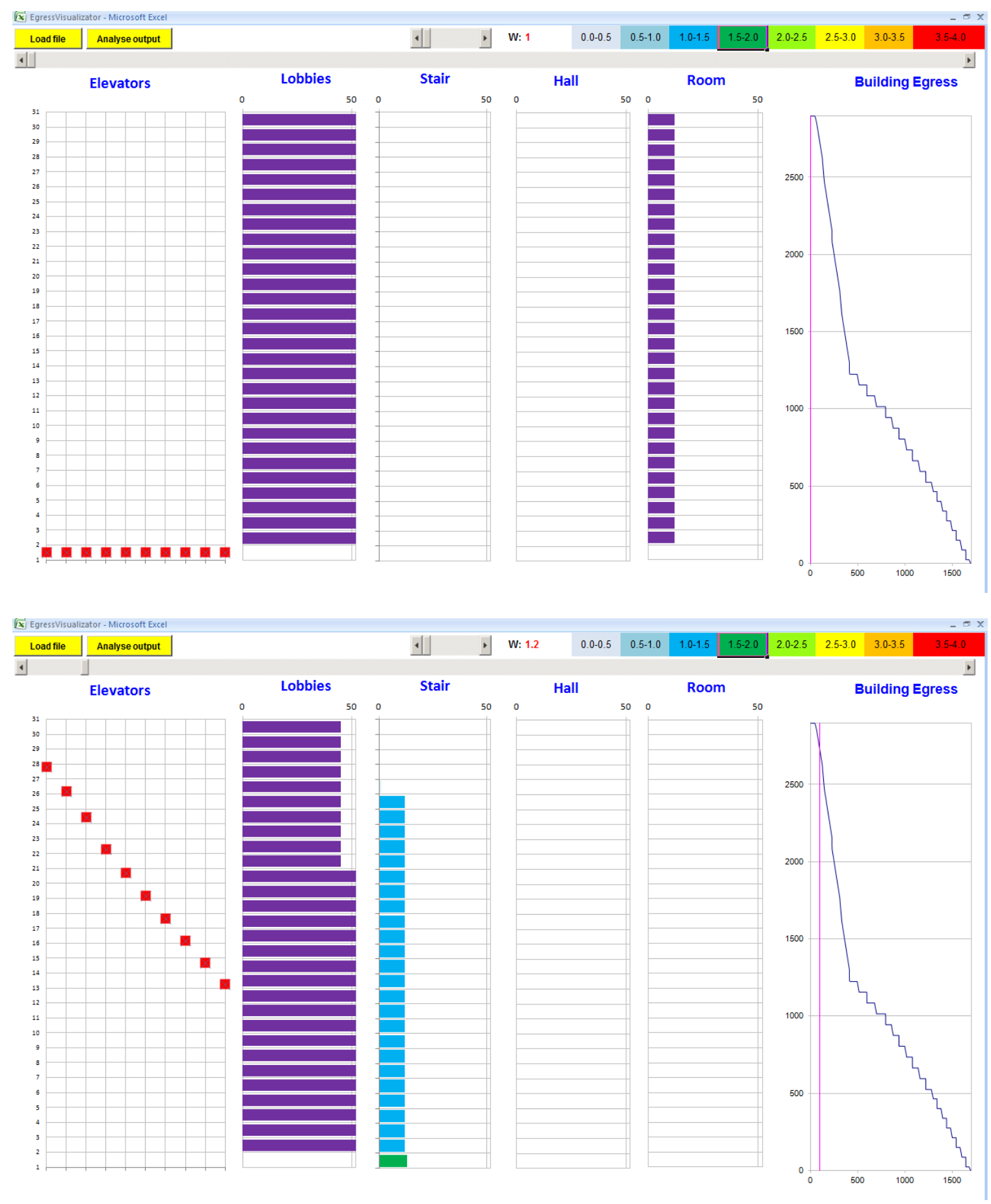
The second screen of the EgressVisualization tool is accessed by pressing the button "Analyse Output". This screen is designed to distill more useful information from the Egress Estimator output. Then, by pressing the button "Select files for analysis" the user can load up one or multiple files (by pressing CTRL during file selection) to observe or compare the progress of egress in the selected output files. This may allow for closer observation of the effects of varying building designs and for testing and comparing egress strategies using stairs and elevators. The output is presented on five graphs. The two leftmost depict the times when each elevator lobby, room or corridor/hall is evacuated. The next graph provides the user with information on how long people are assumed to wait for an elevator. The evacuation of halls/corridors provides information as to when people from a given floor are all within an exit stair, which is considered to be a place of relative safety. The time to leave rooms or halls/corridors can be regarded as the Required Safe Egress Floor (RSET) for a given floor (assuming that elevator lobbies are also considered as a place of relative safety if designed properly). The three other graphs depict the history of egress process in three configurations: total building egress i.e. number of people who remain in the building, total number of people who remain in elevator lobbies on all floors, and the total number of people who remain in stairs and floors (i.e. stairs, halls/corridors and rooms).

The following picture presents a screenshot from the EgressVisualization after loading output data files from EgressEstimator that was run for a 30-floor building in two different design configurations. In this case, there was a different number of elevator cars in the two scenarios. The user can observe effects in total egress total lobby egress times, but the total stair egress remains the same. On the leftmost graph it can be noted that due to different number of elevator cars in one case the lobbies are evacuated sooner than the other case, which also means that the waiting times for people were shorter. The evacuation time of halls/corridors show no difference as there was no difference in stair system design. 


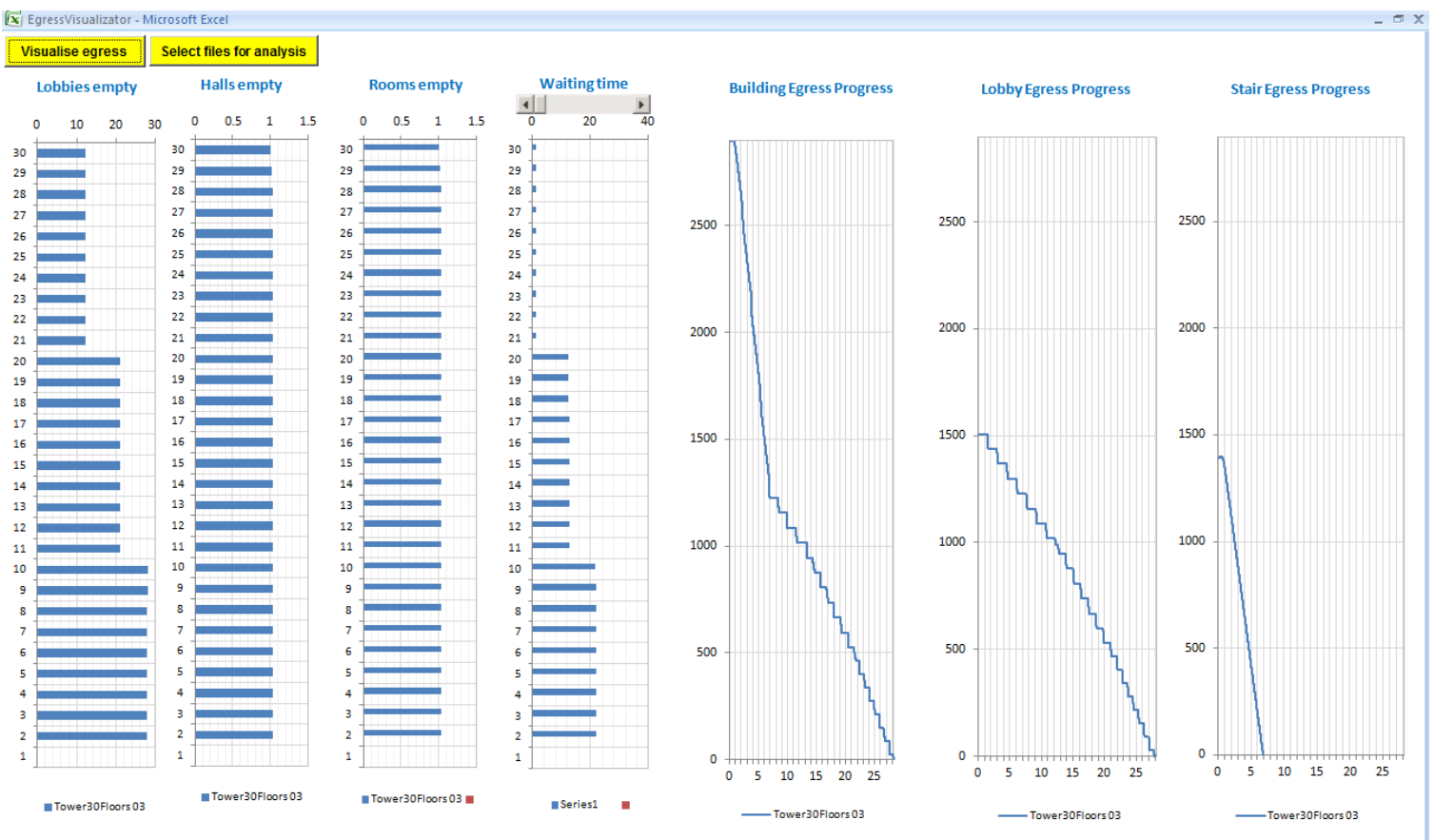

\section{Results}

Egress Estimator was tested for qualitative and/or quantitative agreement with reference sources in addition to comparisons with available experimental evacuation drill data. First, some test cases from International Maritime Organization (IMO) [15] were run to verify that the model was behaving in a reasonable manner for the given parameters. Second, test cases from the SFPE Handbook [6] for stair movement and from a paper by Klote and Alvord [10] for elevator movement were examined to verify that the results were comparable to established methods. Finally, a comparison was made to a set of evacuation drill data previously collected by NIST [16].

\subsection{IMO Criteria}

The IMO regulations include qualification criteria for software used to estimate evacuation times from passenger vessels. While not a true validation of a model, these provide both a qualitative and quantitative assessment of the predictive capability of a model. The criteria were originally designed for agent based evacuation models but they are relevant for all evacuation models. The results of the IMO tests are as follows:

- IMO 1: A person in isolation in a corridor walking at $1.0 \mathrm{~m} / \mathrm{s}$ should travel $40 \mathrm{~m}$ in $40 \mathrm{~s}$.

$\circ$ In Egress Estimator speeds do not change in a clear corridor. The first person in a simulated run meets this criterion. 
- IMO 2 and IMO 3: A person in isolation ascending (or descending) stairs at $1.0 \mathrm{~m} / \mathrm{s}$ should travel $10 \mathrm{~m}$ in $10 \mathrm{~s}$.

- In Egress Estimator, stairs are same as corridors except for the maximum speed. When the speed of an occupant in isolation is $1.0 \mathrm{~m} / \mathrm{s}$, they will travel $10 \mathrm{~m}$ in $10 \mathrm{~s}$.

- IMO 4: In a room with 100 persons and a $1.0 \mathrm{~m}$ door, the flow rate should not exceed 1.33 persons $/ \mathrm{s}$

- In Egress Estimator, flow rates are user specified. When the flow rate is set to 1.33 persons/s or less, this criterion is met.

- IMO 5: Verify that humans begin to move based on a uniform reaction time distribution.

- In Egress Estimator, all occupants begin to move simultaneously with a user-specified pre-evacuation time. Beginning of movement is not based on a uniform distribution.

- IMO 6 A person approaching a corner walks around the obstruction rather than penetrating it.

- In Egress Estimator, there are no corners defined because it is a semione-dimensional model.

- IM0 7: Distribute the walking speed over 50 persons and show that the walking speeds are consistent with the specified input.

- Egress Estimator does not use a walking speed distribution.

- IMO 8 and IMO 9: Verify that the effects from smoke calculated by the model match the expected values.

- Egress Estimator does not consider the effects of smoke.

\subsection{Comparison with empirical correlations for stair movement}

Stair movement correlations have been developed long time ago and they are considered to be well grounded in fire engineering discipline. A good source of these is SFPE Fire Engineering Handbook e.g. in Chapter 14 Emergency Movement by Nelson and Mowrer in the 3rd edition.

The Handbook offers fundamental equations for speed depending on density and the specific flow depending on density. These are empirically derived correlations that are widely accepted in fire engineering field and they form a basis for Egress Estimator. It does not mean that they are not questioned as the curve fit through which they are obtained involves large scatter. Other sources e.g. Russian data suggest that the flow often continues behind the density limit of 4.0 persons per square meter. Nevertheless in fire engineering calculations the SFPE correlations are considered conservative, easy to 
apply and safe to use for simple calculations. Apart from the fundamental speed/density and specific flow/density correlations Handbook offers simple correlations to estimate the egress time from tall buildings (Chapter Movement of People: Evacuation Timing by Proulx). These correlations are given below.

$$
\begin{array}{ll}
\mathrm{T}=0.68+0.081 \mathrm{p}^{0.73} & {[\mathrm{~min}]} \\
\mathrm{T}=2.0+0.0117 \mathrm{p} & {[\mathrm{min}]} \\
\mathrm{T}=0.7+0.0133 \mathrm{p} & {[\mathrm{min}]}
\end{array}
$$

According to the Handbook Eq. X should be used for buildings up to 15 stories high. Equations $\mathrm{Y}$ and $\mathrm{Z}$ are recommended for buildings with respectively below or above 800 occupants per meter of effective stair width.

A comparison study was performed to see how these correlations compare with the Egress Estimator predictions. The table below contains data corresponding to 9 runs of Egress Estimator for a single stair 30 story building and 50 occupants per floor and varying stair width. The correlations $\mathrm{Y}$ and $\mathrm{Z}$ were used in accordance with the abovementioned limit of 800 persons per meter of effective stair width.

\begin{tabular}{|l|c|c|c|c|c|c|c|c|c|}
\hline Stair width [m] & 1.0 & 1.2 & 1.4 & 1.6 & 1.8 & 2.0 & 2.2 & 2.4 & 2.6 \\
\hline Effective Width [m] & 0.7 & 0.9 & 1.1 & 1.3 & 1.5 & 1.7 & 1.9 & 2.1 & 2.3 \\
\hline Population per meter of effective width & 2071 & 1611 & 1318 & 1115 & 967 & 853 & 763 & 690 & 630 \\
\hline Time predicted by SFPE correlations [s] & 1574 & 1251 & 1045 & 903 & 799 & 719 & 651 & 593 & 545 \\
\hline Time as indicated by Egress Estimator [s] & 2372 & 1620 & 1330 & 1133 & 992 & 882 & 796 & 727 & 672 \\
\hline
\end{tabular}
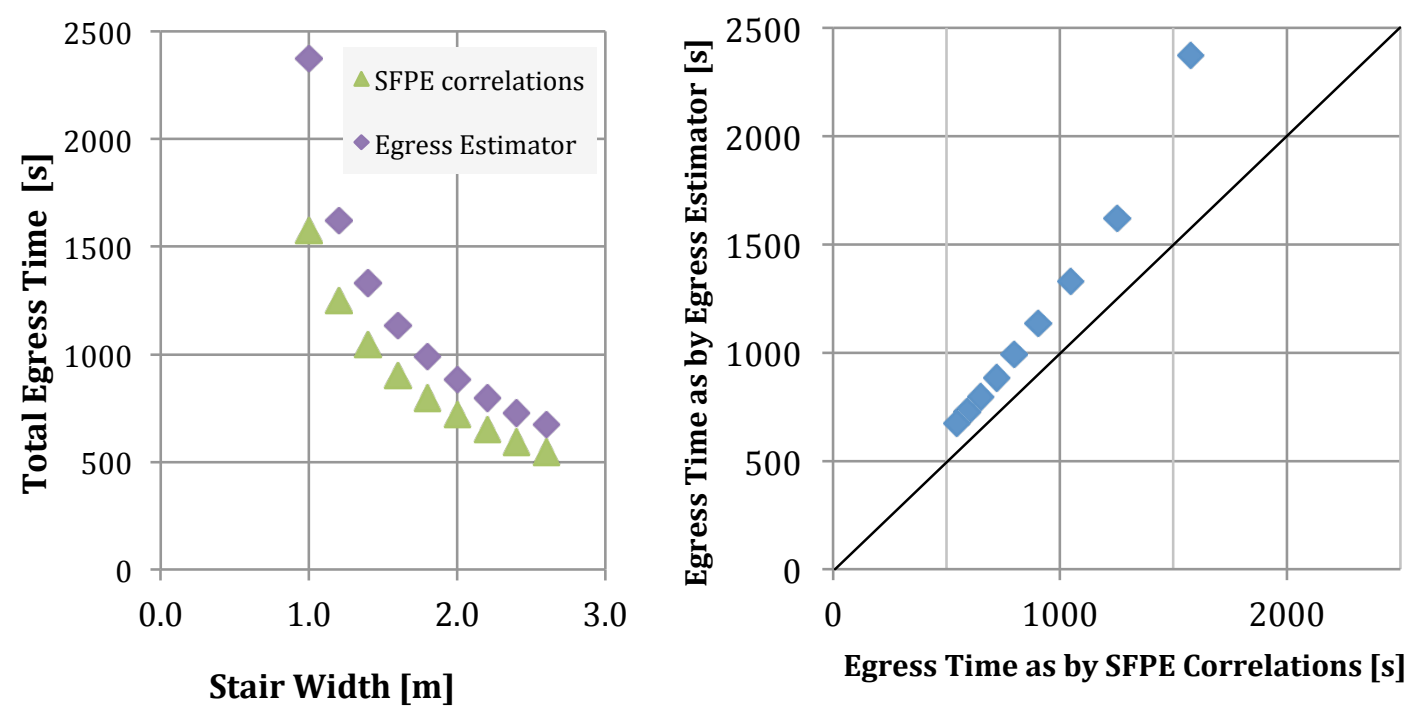

The figures above show that the simple engineering correlations recommended by the SFPE Handbook result in somewhat smaller egress times. The differences are 
proportionally bigger for cases of smaller stair width or bigger population per meter of effective stair width. This effect is explained below.

The transformation of equation 32 and 33 to the format where all terms are in seconds rather than minutes reveals that both formulas involve implicit specific flow rates i.e. the flow per meter of effective stair width.

$$
\begin{array}{ll}
\mathrm{T}=120+\mathrm{p} / 1.425 & {[\mathrm{~s}]} \\
\mathrm{T}=41+\mathrm{p} / 1.253 & {[\mathrm{~s}]}
\end{array}
$$

These specific flows are noticeably bigger than the maximum specific flows that consequently result from the fundamental speed/density correlation and which are specified in the figure and table from the SFPE Handbook reproduced below.
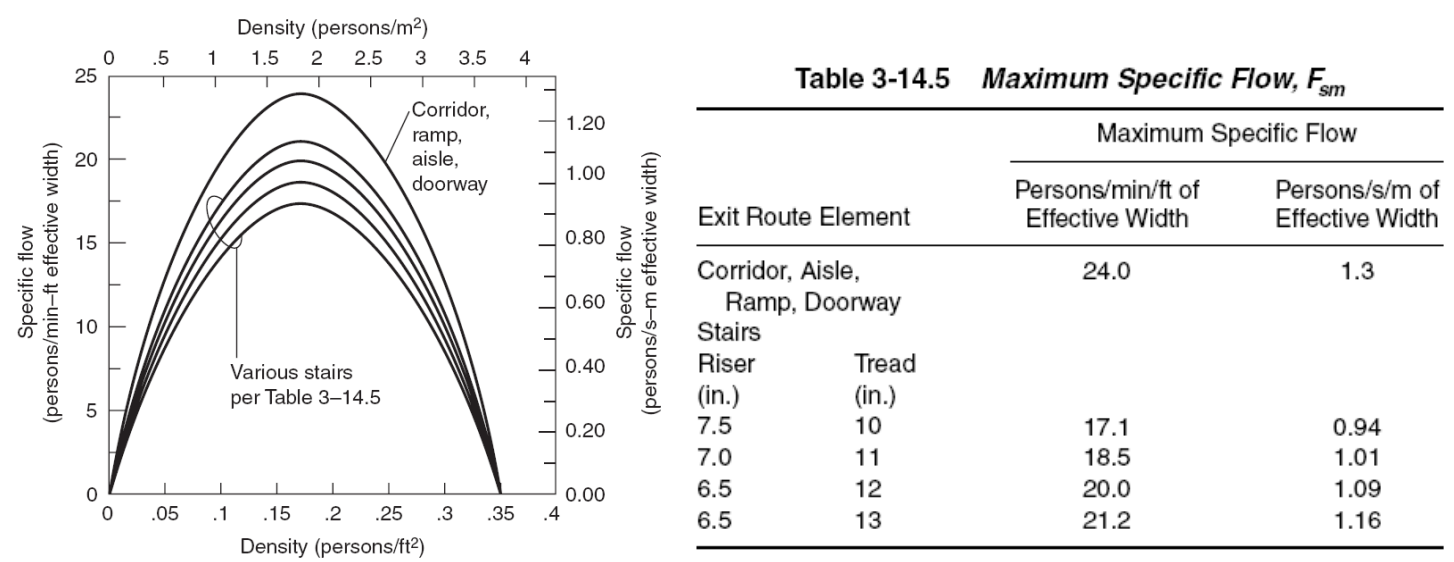

The bigger specific flow rates result in faster egress times predicted by the SFPE tall building egress time correlations. This difference in specific flow rates seems to be related to the conservative nature of the fundamental speed/density correlation. The experimental data from unannounced evacuation drills implies bigger values of specific flow rate. As the Egress Estimator is based on this fundamental correlation it can be expected that the emerging specific flows will be closer to the maximum specific flows resulting from the fundamental speed/density correlation. Further analysis of Egress Estimator predictions is continued below.

First a qualitative view is presented to discuss the characteristics of the flow in the stairwell and the distribution of occupants across the height of the building. Results from the previously mentioned study of a single stair 30 story building with varying stair width is used.

The effects of changing the stair width are clearly seen in the distribution of occupants in the stairwell. In the graphical example below there are no restrictions on flow rate from each floor and at the bottom of the stair so there are no additional influences on the flow apart from the stair itself. Despite the same interval after the initiation of the evacuation each picture represents slightly different phase of egress in terms of flow uniformity across the floors. This depends on whether the floors are already empty or not. If not, the 
lowest point of flow convergence defines a height from which the density decreases gradually. This effect of flow decompression could be expected in reality. If the flow is not slowed down due to flow convergence it tends to be more uniform in terms of density across the floors.

\begin{tabular}{|c|c|c|c|c|c|c|c|}
\hline Density & $0.0-0.5$ & $0.5-1.0$ & $1.0-1.5$ & $1.5-2.0$ & $20-25$ & $25-30$ & $3.0-3.5$ \\
\hline
\end{tabular}
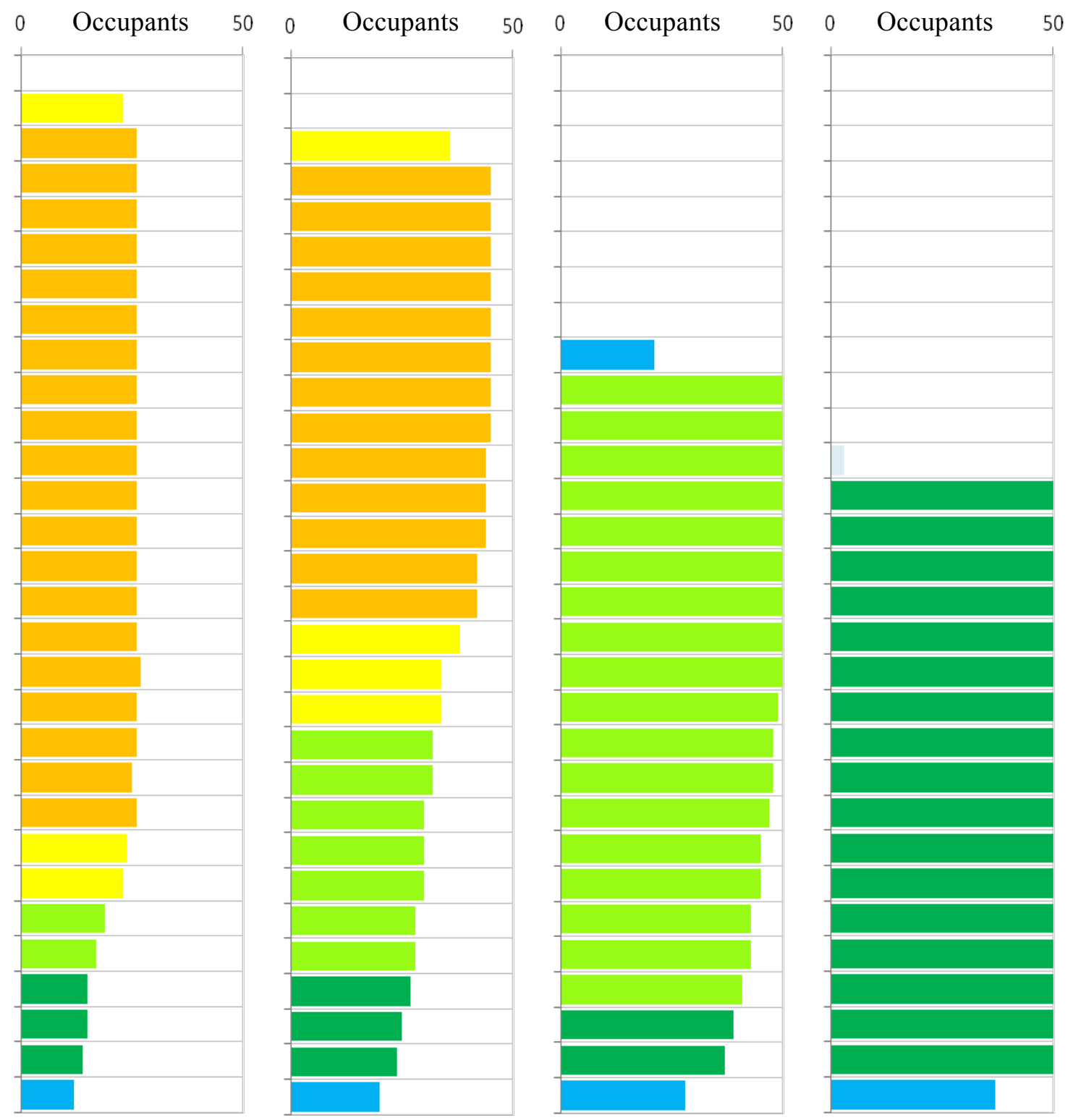

Fig. X. Distribution of occupants in the stairwell across the height of the 30 story building taken 5 minutes after the initiation of evacuation. Four cases represent four stair widths: $1.2,1.6,2.0$ and $2.4 \mathrm{~m}$. 
It can be noted that the wider the stair the more people can enter the stairwell, and the less time is needed for egress. Consequently, the end of the flow is located visibly lower. As the standing area of landings and flights increases, the density decreases. Interestingly, the density at the bottom of the stair is similar in all cases. This suggests that the characteristic flow at the critical section of the stair is probably similar regardless of the stair width. This is confirmed in further analysis.

The occupant flow at the bottom of the stair in 9 cases was analyzed excluding the period when the occupants have not yet reached the bottom of the stair. This leaves very linear flow histories in all cases which can be easily trendlined and the slope can be established. The slope is the flow out of the stairwell in persons per second. All estimator runs are presented in the figure below with corresponding trendline function and $\mathrm{R}^{2}$ value.

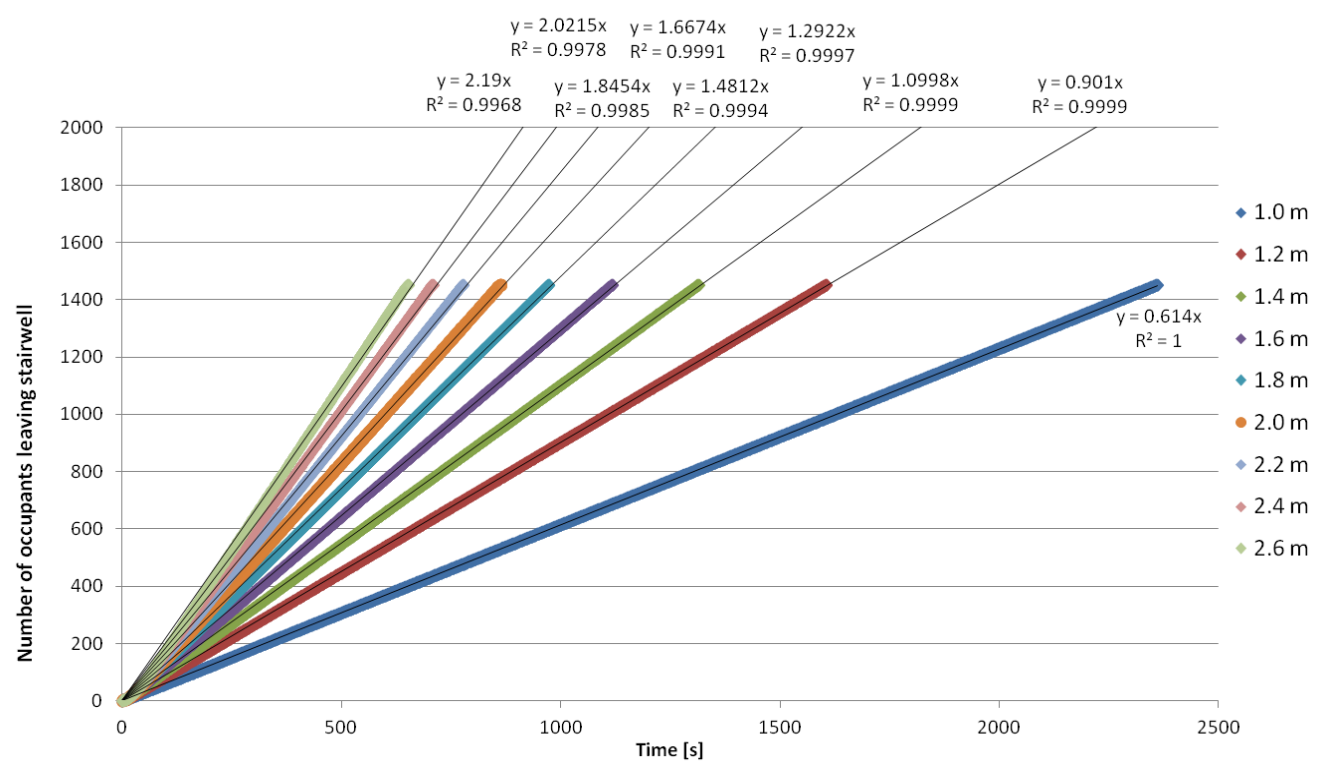

Linear slope coefficients obtained at this stage are then plotted against the stair width which can be seen on the next figure. This gives two series of data points for full width and effective width that turn out to fit linear functions very closely. The line corresponding to the effective appears to be more useful as it crosses the 0,0 point which suggests that the characteristic flow measured in persons $/ \mathrm{s} / \mathrm{m}$ is similarly proportional to the effective widths in all cases. The slope of the curve fitted function for the effective width is 0.97 . Characteristic flow derived in such way corresponds quite closely with the maximum specific flow for this stair configuration ( 7 inch riser, 11 inch tread) as given by the SFPE Fire Engineering Handbook and reproduced in this section. This suggests that the flow conditions generated by the Egress Estimator are emerging as close to the optimal maximum flows for a given stair width. The consistent value of specific flow also allows for quick and simple prediction of the Egress Estimator output for simple cases of simultaneous egress of buildings with uniform distribution of population on all 
floors. It may not to be consistent with cases of tall buildings and small populations per floor as the flow may be much smaller.

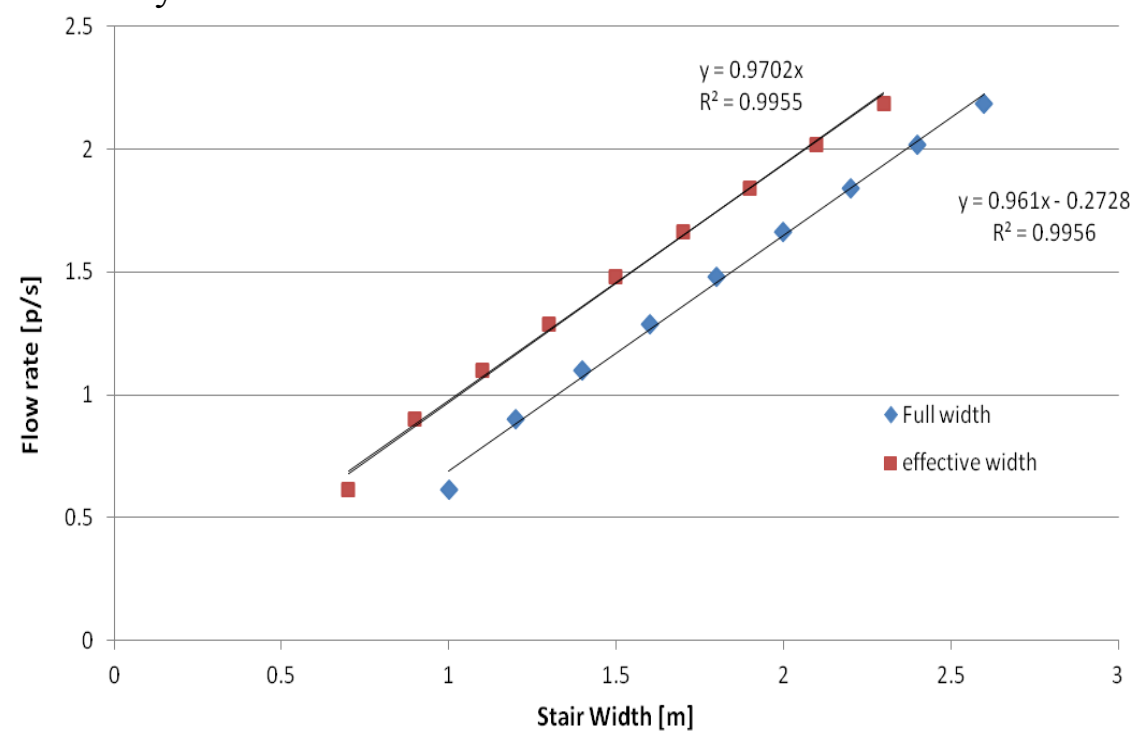

The above study confirms robustness of estimations made by Egress Estimator and its consistency with the fundamental SFPE egress speed/density correlation. It opens up a question however of whether this correlation is not overly conservative and of what should be the recommended correlation for egress modeling using computer models in cases when the realism of results is the object of the study.

\subsection{Comparison with ELVAC Calculations}

Next the elevator portion of Egress Estimator was compared to a published sample problem. ELVAC [10] calculated the time required for five $1600 \mathrm{~kg}(3500 \mathrm{lbs})$ elevators with $1.2 \mathrm{~m}$-wide, center-opening door to evacuate 90 persons per floor from the top 11 floors of a 21 floor building and 3 persons per floor from the lower floors in the building. The floors were $3.2 \mathrm{~m}$ high. Each car had a maximum capacity of 16 passengers, maximum velocity of $3.0 \mathrm{~m} / \mathrm{s}$, and acceleration of $1.2 \mathrm{~m} / \mathrm{s}^{2}$. For this problem, Klote calculates a time of $1258 \mathrm{~s}$. Using Klote's calculation method, the time required to evacuate 90 persons from all floors would be $1842 \mathrm{~s}$. Using the same assumptions, Egress Estimator calculated an evacuation time of $1835 \mathrm{~s}$. Egress Estimator is within $1 \%$ of the time calculated by ELVAC. 


\subsection{Comparison with Evacuation Drill Data}

While there is a lack of data on elevator evacuations, NIST has an ongoing project to collect stair movement data during fire drill evacuations [16]. In the study, fire drill evacuations were monitored by positioning video cameras out of the way of building occupants to record an overhead view of occupant movement in an exit stair during the evacuation. In most buildings, unless specified, the video cameras were placed on every other floor to capture a view of that floor's main landing, the door into the stair at that level, and 2 steps to 3 steps on each side of the main landing (leading to and from the main landing). This camera placement captured the times in which the occupant was seen moving past a particular floor landing as well as the time when he/she was seen moving into the stairs.

After video data was taken from each building evacuation drill, NIST transcribed specific data from the videos into a spreadsheet format for each stair monitored during the drill. For each stair recorded, data were collected 1) for each occupant evacuating in that stair and 2) for each time during the evacuation drill that the occupant was seen at a specific floor in the stair (a camera position), typically both entering and exiting the camera view.

The data is recorded to the nearest $0.01 \mathrm{~s}$ with a maximum estimated uncertainty of less than $\pm 0.5 \mathrm{~s}$. All data is rounded to the nearest second because higher precision serves no purpose. Including rounding error the maximum uncertainty is $\pm 1.0 \mathrm{~s}$. Model data is given to $0.2 \mathrm{~s}$ to emphasize that it is a model calculation using time steps of exactly $0.2 \mathrm{~s}$ giving high precision but possibly low accuracy.

Data from a total of four stairwells in three different buildings are used to compare against predictions made by the Egress Estimator.

Building 8 is a 31-story office building on the East Coast of the United States. The building has two stairs (North and South) that both exit on the 2nd floor onto the street level. The two stairs are $1.38 \mathrm{~m}$ (54.3 in) wide, $1.26 \mathrm{~m}$ (49.8 in) between the handrails. There are two flights of 9 steps separated by a landing between each floor with the individual steps measuring $0.18 \mathrm{~m}$ (7.0 in) for the rise and $0.27 \mathrm{~m}(10.8 \mathrm{in})$ for the tread depth. For the Egress Estimator calculation, transfer corridors and additional steps leading to the discharge level were excluded resulting in a decreased travel distance. The exit door in the South stair is approximately $0.88 \mathrm{~m}$ wide (34.8 in) and the North exit door is about $1.02 \mathrm{~m}$ wide (40.0 in) both with door closers. Assuming a flow of 0.92 people/meter of width that gives a maximum flow of 0.81 people/s out of the South stair and a maximum flow of 0.94 people/s out of the North stair.

The North stair of Building 8 had 652 persons above the second floor evacuate during the first $1072 \mathrm{~s} \pm 1 \mathrm{~s}$ of the drill. For this scenario, Egress Estimator used 667 people to evenly distribute people in the building. The calculated total evacuation time was $887 \mathrm{~s}$. This prediction has an error of $17.2 \%$ than the actual experiment. The graph in Figure 3 
shows the cumulative number of people that have evacuated for the experimental data including stragglers, the Egress Estimator prediction, and two times the prediction to bracket the experimental data.

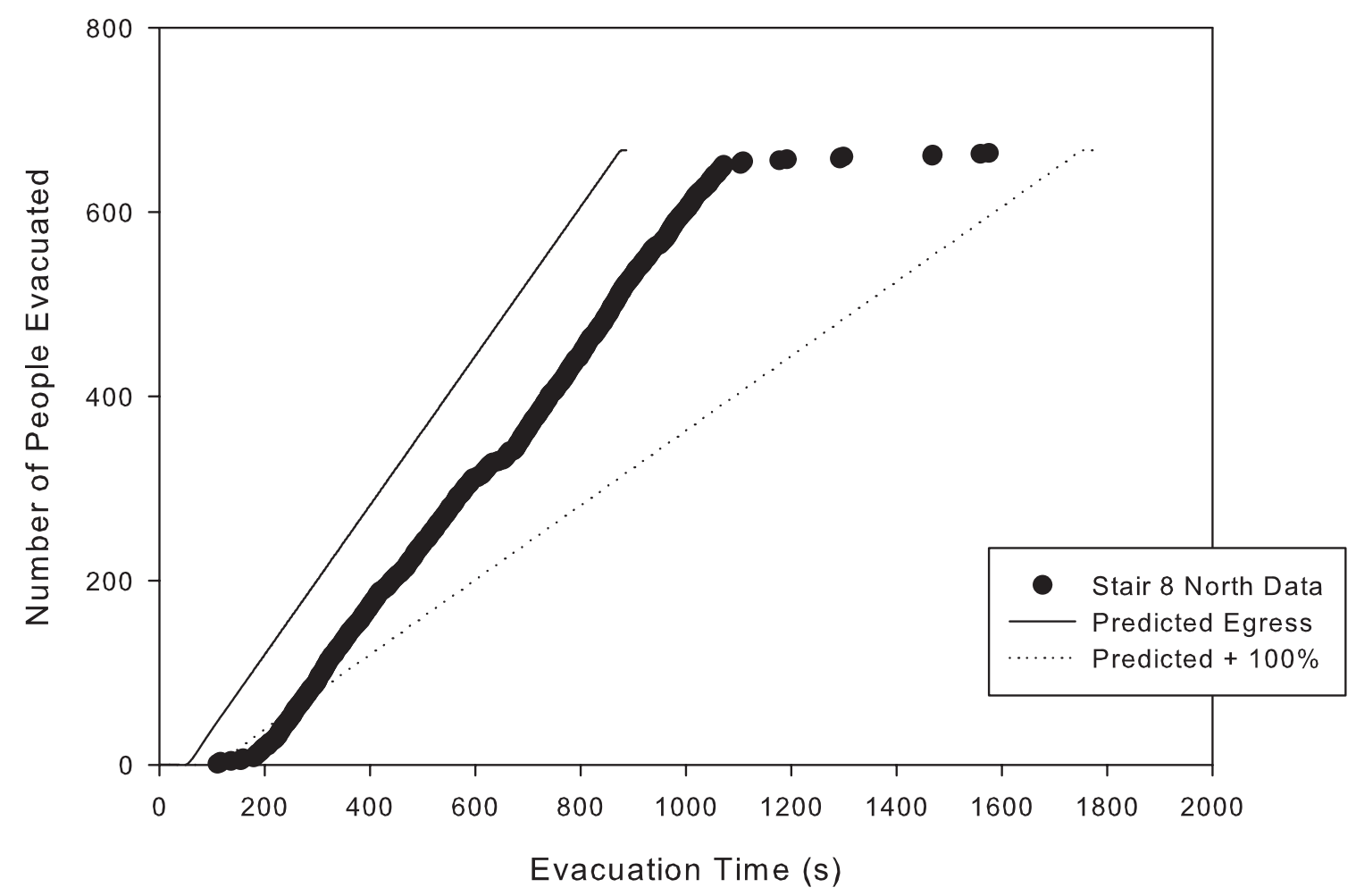

Figure 3. Stair 8 North data with the prediction of Egress Estimator and twice the prediction. Uncertainty is $\pm 1 \mathrm{~s}$.

The south stair has 525 people who evacuate but the last 74 follow an evacuee who had significant difficulties with the stairs. A total of 522 were used divided evenly among all the floors in the Egress Estimator simulation. The predicted time to evacuate was $708 \mathrm{~s}$ while the actual egress time was $1002 \mathrm{~s} \pm 1 \mathrm{~s}$ for an error of $29.3 \%$. Figure 4 shows all the evacuation data bracketed by the Egress Estimator calculation and twice the calculation as in the graph of the North stair data in Figure 3.

Notice that the data has the evacuation broken into two groups. The larger one is first and the Egress Estimator does a much better job predicting the egress time and a second smaller group that comes down significantly later. The second group followed an evacuee that had significant physical difficulties negotiating the stairs and so everyone was slowed following him/her. 


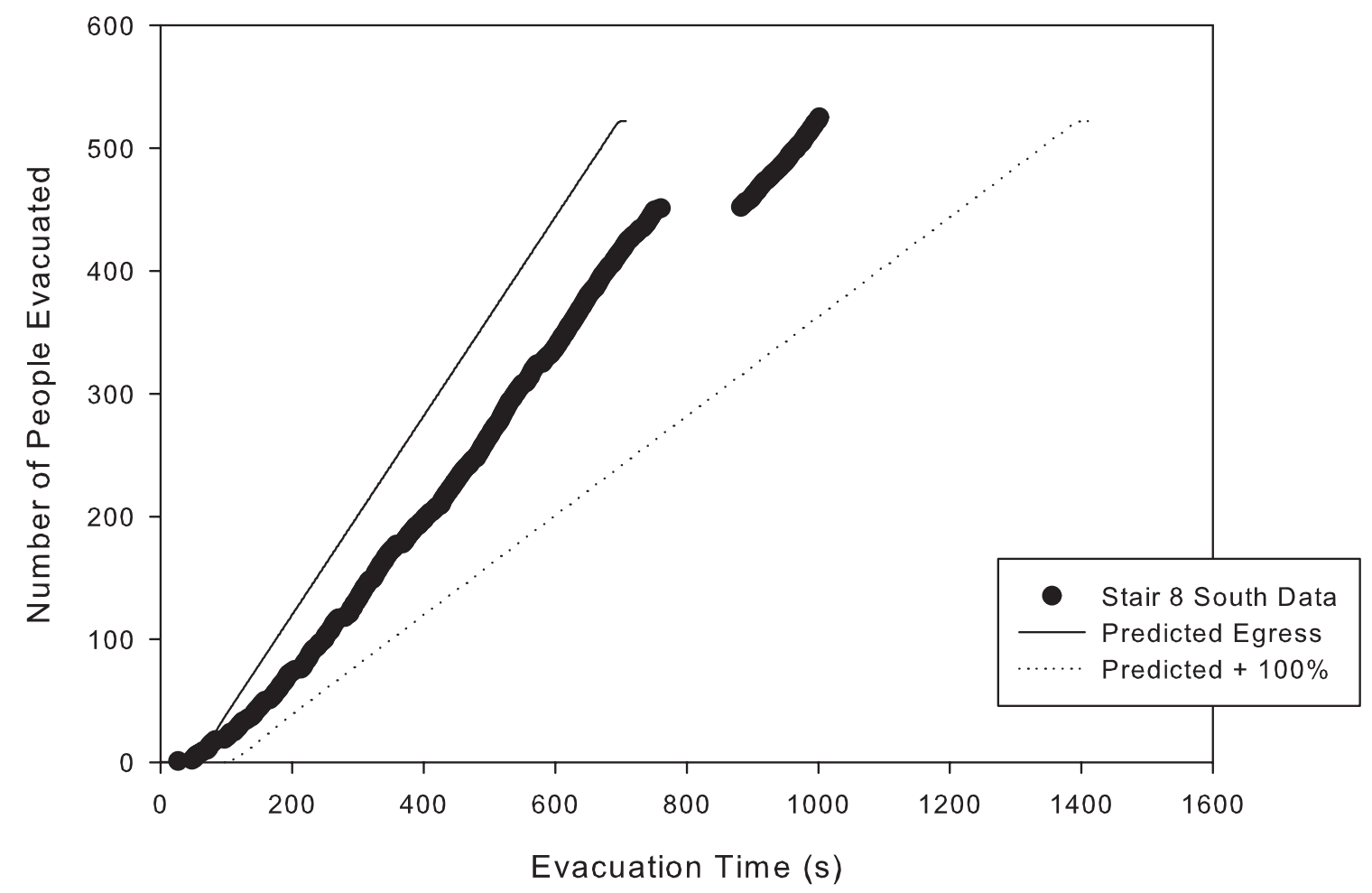

Figure 4. Comparison of Stair 8 South data and Egress Estimator prediction and twice prediction. Uncertainty is $\pm 1 \mathrm{~s}$.

Because the Egress Estimator is a screening tool it doesn't attempt to account for evacuees that are significantly slower than the average person. For applicability of the data, the analysis of the south stair is done with the first 451 people. The Egress Estimator used 464 people evenly divided among all the floors. In the evacuation the first 451 people left the building in about $761 \mathrm{~s} \pm 1 \mathrm{~s}$. The Egress Estimator calculated a time of $636 \mathrm{~s}$ for an error of $16.4 \%$ faster than the drill. Figure 5 shows Stair 8 South egress data and the Egress Estimators prediction of the first 464 people as well as twice the calculation. 


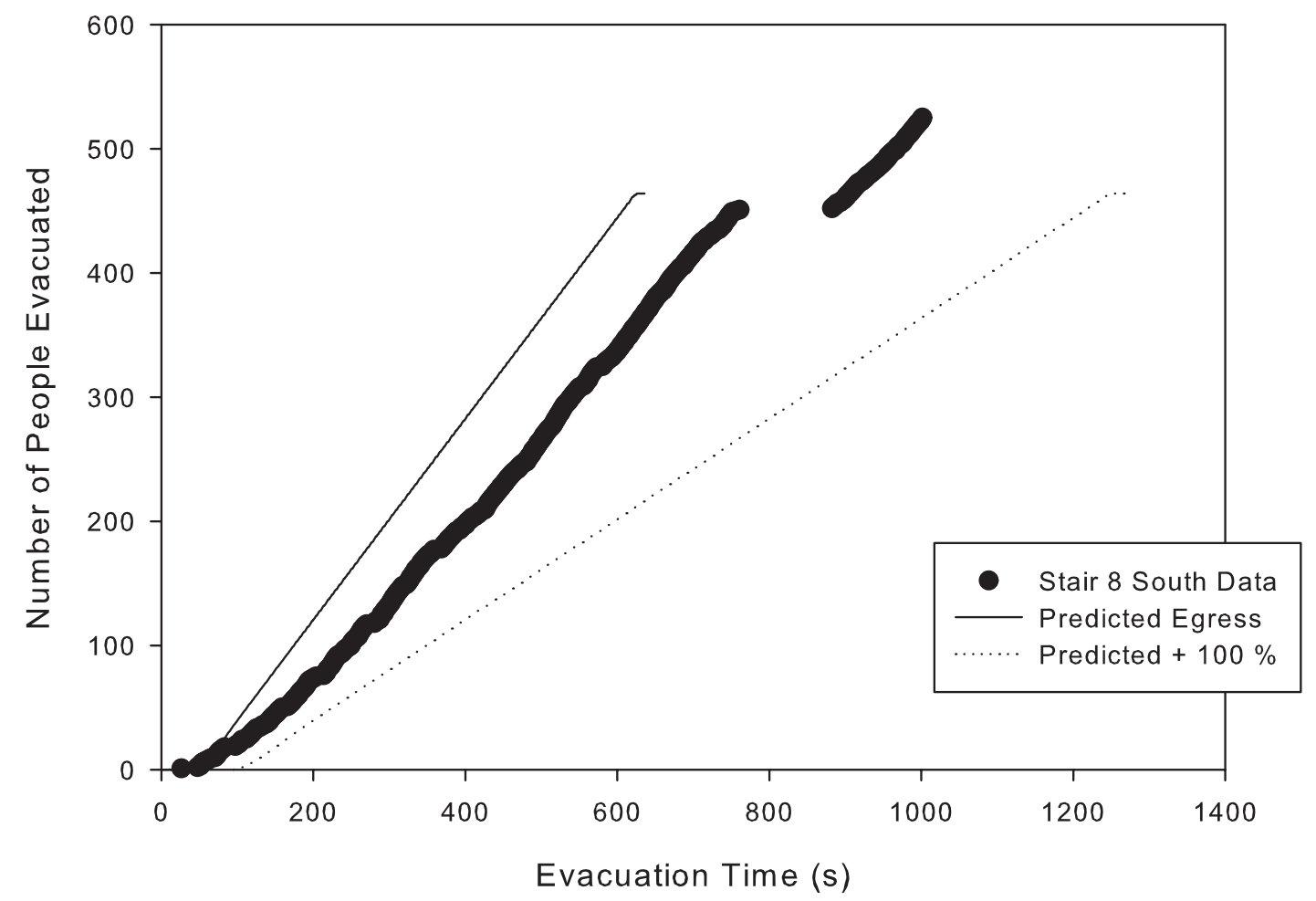

Figure 5. Comparison of Stair 8 South data and Egress Estimator prediction and twice prediction. Uncertainty is $\pm 1 \mathrm{~s}$.

The third example is a West Coast Building designated as Building 5. Two stairs were monitored, however, only stair A is used in this analysis since counterflow (not account for in the model) took place in stair B. Building 5 has 10 stories and the stair A exit on the first floor. Between each floor are two flights of 11 steps with a landing in between. The steps are $1.27 \mathrm{~m}(50 \mathrm{in})$ wide, $1.22 \mathrm{~m}$ (48 in) between the handrails with the risers and treads measuring $0.18 \mathrm{~m}$ (7 in) by $0.28 \mathrm{~m}$ ( $11 \mathrm{in})$. On the first floor, the stairs lead into a $1.37 \mathrm{~m}$ (54 in) wide hallway that took evacuees outside. The actual exit door is not observed, so a maximum flow rate of 1.26 people/s is used in the model run.

A total of 432 people used stair A with three individuals following well behind the main mass of evacuees. The Egress Estimator used 432 people in its prediction. The Egress Estimator calculated an egress time of $533 \mathrm{~s}$ while the actual evacuation took about $628 \mathrm{~s} \pm 1 \mathrm{~s}$ for an error of $15.1 \%$ faster than the drill. The cumulative plot of the data and the bracketing estimates from the Egress Estimator are shown in Figure 6. 


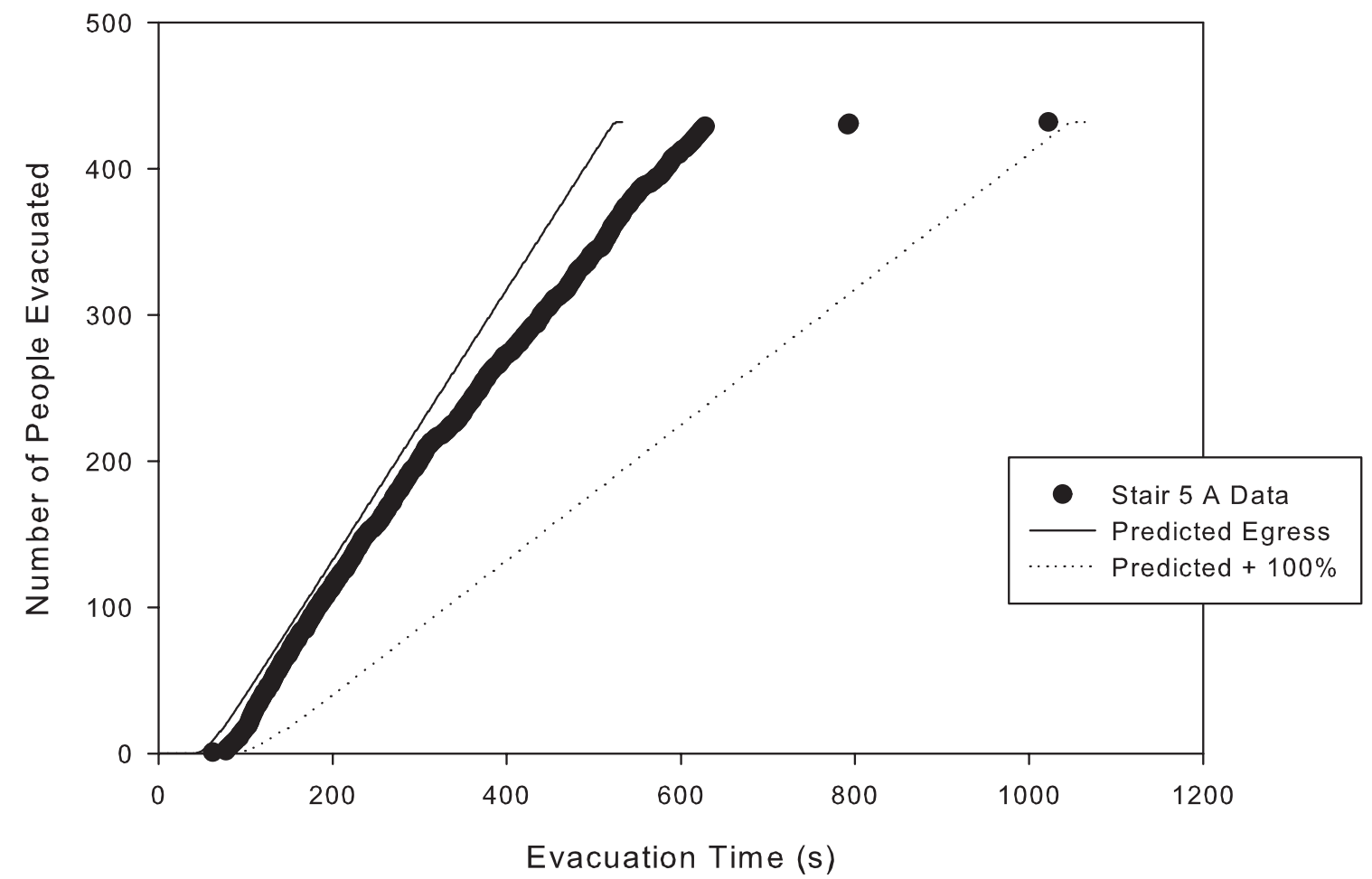

Figure 6. Comparison of Stair 5 A and Egress Estimator prediction and twice prediction. Uncertainty is $\pm 1 \mathrm{~s}$

The last comparison example used is a 24 story West Coast office building designated as Building 4. Again two stairs were monitored but in one stair firefighters entered during the evacuation. Stair B, used in this example, exited directly outside on the first floor. The width of Stair B is $1.12 \mathrm{~m}$ (44 in) wide, measuring $1.02 \mathrm{~m}$ (40 in) between the handrails, and had $0.18 \mathrm{~m} \mathrm{(7} \mathrm{in)} \mathrm{risers} \mathrm{and} 0.28 \mathrm{~m}$ (11 in) treads. Between each floor were two flights of stairs with 10 steps each with a landing in the middle. The exit is $1.09 \mathrm{~m}$ (43 in) wide giving a maximum flow of 1.0 person/s.

The 348 people in the main mass in Stair B completed their evacuation in about $650 \mathrm{~s} \pm 1$ s. The 345 people used in the Egress Estimator completed the evacuation in $511 \mathrm{~s}$ for an error of $21.4 \%$ faster. The cumulative graph of evacuation data and prediction are shown in Figure 7. 


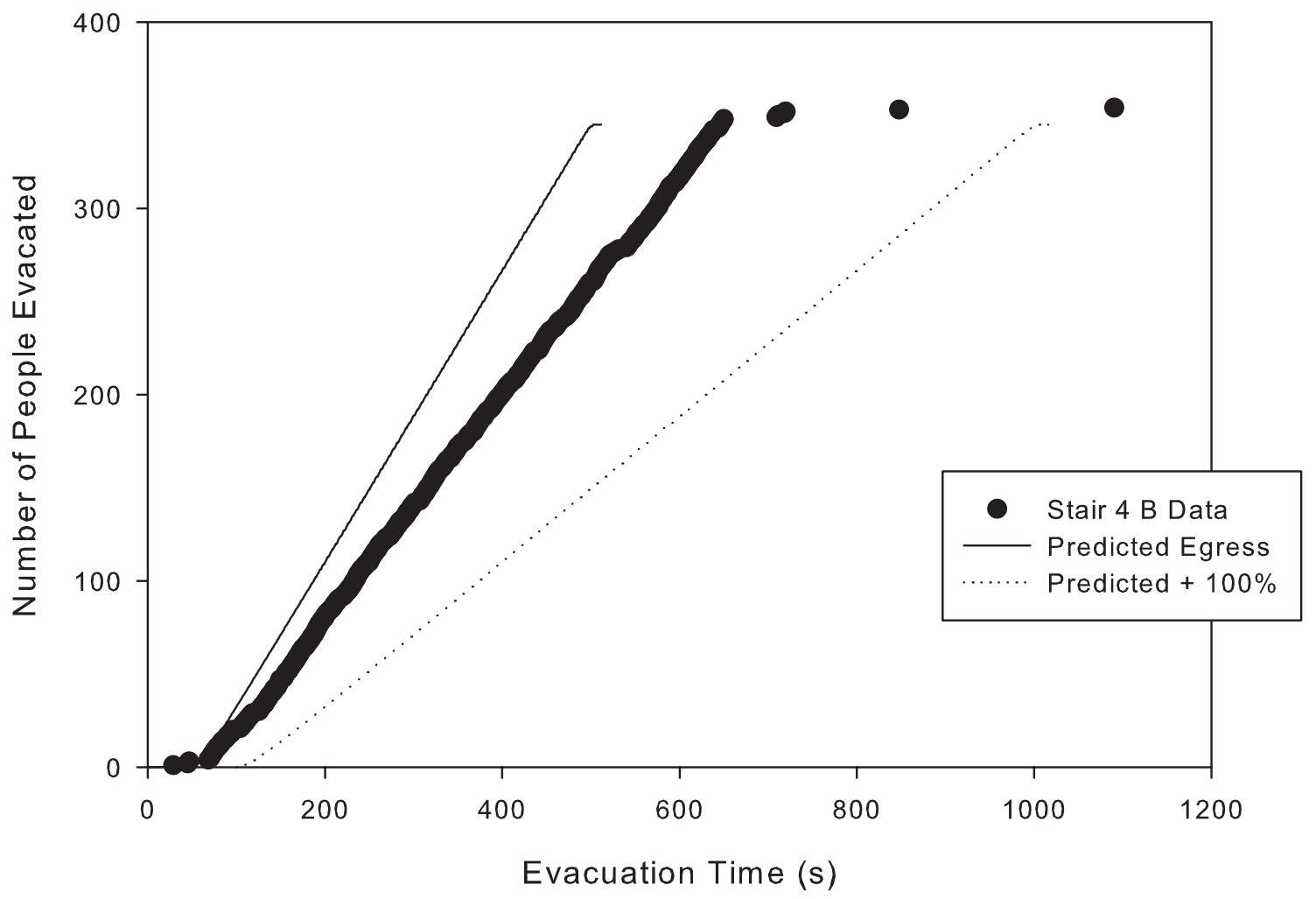

Figure 7. Comparison of Stair $4 \mathrm{~B}$ data and Egress Estimator prediction and twice prediction. Uncertainty is $\pm 1 \mathrm{~s}$.

Table 2. Summary of comparison of egress data with Egress Estimator predictions

\begin{tabular}{|c|c|c|c|c|c|c|}
\hline Stair & $\begin{array}{l}\text { Prediction } \\
\text { Population }\end{array}$ & $\begin{array}{l}\text { Evacuation } \\
\text { Population } \\
\end{array}$ & \% Diff & Prediction & $\begin{array}{l}\text { Evacuation } \\
\text { Time }\end{array}$ & $\%$ Error \\
\hline 8 North & 667 & 652 & $2.03 \%$ & 887 & 1072 & $-17.2 \%$ \\
\hline 8 South & 522 & 525 & $-0.57 \%$ & 708 & 1002 & $-29.2 \%$ \\
\hline 8 South (sub) & 464 & 451 & $2.80 \%$ & 636 & 761 & $-16.4 \%$ \\
\hline $5 \mathrm{~A}$ & 432 & 432 & $0.0 \%$ & 533 & 628 & $-16.1 \%$ \\
\hline $4 \mathrm{~B}$ & 345 & 348 & $-0.86 \%$ & 511 & 650 & $-21.4 \%$ \\
\hline
\end{tabular}

Table 2 summarizes the results. Included in the table is the population used in the Egress Estimator, the population from the evacuation and the percentage difference. Notice that the percentage error in the calculation compared to that actual evacuation is less than the percentage difference in the populations. This implies the model is predicting movement a bit fast even if the populations matched perfectly.

Another thing to note from the table is that Stair $4 \mathrm{~B}$ and Stair 8 South are the worst prediction and significantly different compared to the other predictions. The reason for the difference in Stair 8 South has already been discussed. The significant difference between Stair $4 \mathrm{~B}$ and the other stairs is that there were very few instances of people 
passing other people or of the population forming two lanes on the stairs. [17] In the other evacuations there was significant number of instances of both behaviors.

In order to gain a better understanding of how the Egress Estimators calculations look overall it would be helpful to compare the four cases. Normalizing each of the plots using the time and number of evacuees used in each case, the graphs can be combined. The results are in Figure 8.

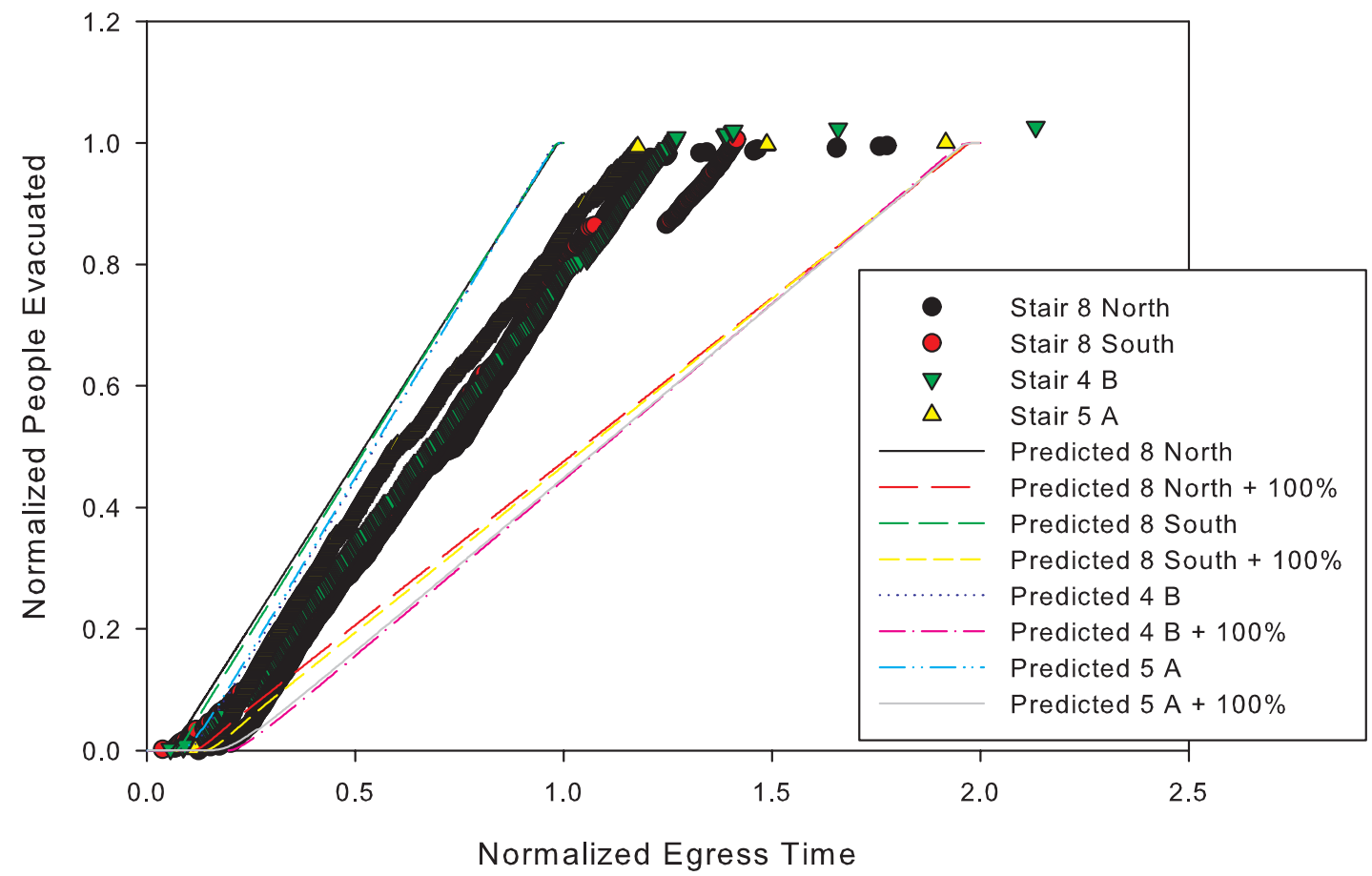

Figure 8. Normalized data from all stairs as compared to predictions of Egress Estimator. Uncertainty is less than \pm 0.004 .

As can be seen the main mass of all the evacuations are actually completed within $125 \%$ of the time calculated by the Egress Estimator. Even including all the stragglers everyone evacuates in less than twice the time predicted by the Egress Estimator. As a screening tool this provides a reasonable first estimate of the evacuation time of a building.

\subsection{Limitations}

It is important to keep in mind what the Egress Estimator is and is not. It is a simple screening tool to help in the design of multi-story buildings. The purpose is to establish broad design parameters based on some simple calculations.

The model assumes a simplified design on the building's stair and elevator egress systems. It makes assumptions about how individual behaviors average out to the population's behavior. 
There are a number of limitations to keep in mind when using the Egress Estimator. The first is the limited amount of validation work that has been done so far. The stair model has only been validated against a small set of data. Because of a lack of data, the elevator model hasn't been validated.

The Egress Estimator is not the tool for final validation analysis of a design. It doesn't handle a number of phenomena that would be important to consider in a final design including but not limited to:

- Mobility challenged evacuees

- Counter flow

- Uneven distribution of the population among floors

- Different demographic distributions of the population

- Stairs with differing designs in the same building

- The effects of smoke and/or fire

- The effects of building damage. 


\section{Conclusion}

A computer model for estimation of egress time for combined stairwell and elevator evacuation is described. The model is intended as a screening tool to make simple estimates of the impact of some of the parameters in an egress system design. The model allows for the inclusion of both elevators and stairs in the egress system.

The model uses a one-dimensional partial differential equation sub-model to estimate the flow of people down stairs based on the SFPE Handbook. The elevator model is based on the model ELVAC but differs in the use of an explicit elevator control model.

When the Egress Estimator is compared to the models that serve as the basis of the Egress Estimator the results show a good agreement. The Egress Estimator comes within $1 \%$ of the example given by Klote and Alvord for ELVAC.

Comparing the stairs model to model to collected fire drill data the few individuals with significantly longer egress times, also known as stragglers, were excluded. When the flow model in the Egress Estimator was compared against fire drill evacuation data, it was found that the model's predicted total egress time was within $15 \%$ of the measured time for the range of experiments studied. To account for stragglers when evaluating designs appropriate design margins should be considered. 


\section{References}

1 NIST. "Strategic Roadmap for Fire Risk Reduction in Buildings and Communities" Natl. Inst. Stand. Technol., Special Publication (2011).

2 NBS. Design and Construction of Building Exits. National Bureau of Standards Miscellaneous Publication M151. National Bureau of Standards. Washington, DC. October 10, 1935. Document can be found at: http://www.nist.gov/el/fire_research/egress.cfm.

3 Fruin, J. J., Pedestrian Planning and Design, Metropolitan Association of Urban Designers and Environmental Planners, Inc., New York, NY, 1971.

4 Fruin, J.J. Pedestrian Planning and Design, Revised Edition). ElevatorWorld, Inc., Mobile, AL, 1987.

5 G. Proulx. "Movement of People: The Evacuation Timing." Chapter 3-13, pages 3-341 - 3-366. In The SFPE Handbook of Fire Protection Engineering. Society of Fire Protection Engineers, Bethesda, MD, third edition, 2002.

6 Nelson, H. E. and F. W. Mowrer, "Emergency Movement," Chapter 3-14 in SFPE Handbook for Fire Protection Engineering, $3^{\text {rd }}$ Ed., National Fire Protection Association and Society of Fire Protection Engineering (2002).

7 Hoskins, B. L., "The Effects of Individual Characteristics and Group Dynamics on Egress on Stairs." PhD Thesis, University of Maryland, College Park, 2011.

8 Kuligowski, E. D., Peacock, R. D., and Hoskins, B. L., "A Review of Building Evacuation Models, 2nd Edition," Natl. Inst. Stand. Technol., Technical Note 1680 (2010).

9 Klote, J.H., An Overview of Elevator Use for Emergency Evacuation. CIB-CTBUH Conference on Tall Buildings. Proceedings. Task Group on Tall Buildings: CIB TG50. CIB Publication No. 290. October 20-23, 2003, Kuala Lumpur, Malaysia, Shafii, F.; Bukowski, R.; Klemencic, R., Editors, 175-185 pp., 2003.

10 Klote, J. H., "Method for Calculation of Elevator Evacuation Time," J. of Fire Protection Engineering, Vol. 5, No. 3, 86-96 (1993).

11 Lord, J., B. Meacham, A. Moore, R. Fahy, and G. Proulx, "Guide for Evaluating the Predictive Capability of Computer Egress Models," Natl. Inst. Stand. Technol., Grant Report, NIST GCR 06-886 (2005)

12 Pauls, J. L., Evacuation Drill Held in the BC Hydro Building 26 June 1969, National Research Council of Canada, Building Research Report 80, 1971.

13 Kuligowski, E. D. and R. D. Peacock, "Review of Building Evacuation Models," Natl. Inst. Stand. Technol., Technical Note 1471 (2005).

14 Gwynne, S.M.V, Kuligowski, E.D., Kratchman, J., Milke, J.A., "Questioning the Linear Relationship Between Doorway Width and Achievable Flow Rate," Fire Safety Journal, 44 (2009) 80-87.

$15 \mathrm{IMO}$, "Interim guidelines for evacuation analyses for new and existing passenger ships", MSC/Circ.1033, International Maritime Organization, London, (2002).

16 Kuligowski, E. D. and Peacock, R. D., "Building Occupant Egress Data," Report of Test FR 4024, Natl. Inst. Stand. Technol., Gaithersburg, MD (2010). 
17 Hoskins, B.L., "The Effects of Individual Characteristics and Group Dynamics on Egress on Stairs." PhD Thesis, University of Maryland, College Park, 2011. 